LEONARDO FREITAS DE MORAES E CASTRO

\title{
CONCEITO DE BENEFICIÁRIO EFETIVO NOS ACORDOS INTERNACIONAIS CONTRA A BITRIBUTAÇÃO
}

\author{
DisSERTAÇÃo De Mestrado
}

ORIENTADOR: PROFESSOR DOUTOR GERD WILLI RoTHMANN

FACULDADE DE DIREITO DA USP

SÃO PAULO

2012 


\section{CONCEITO DE BENEFICIÁRIO EFETIVO NOS ACORDOS INTERNACIONAIS CONTRA A BITRIBUTAÇÃO}

Dissertação apresentada como requisito parcial para a obtenção do título de Mestre pelo Programa de PósGraduação da Faculdade de Direito da Universidade de São Paulo, sob a orientação do Professor Doutor Gerd Willi Rothmann

FACULDADE DE DIREITO DA USP

SÃO PAULO

2012 


\section{RESUMO}

O conceito de beneficiário efetivo nos acordos internacionais contra a bitributação, apesar de não expressamente definido, é um requisito específico para que pessoas possam usufruir das disposições relativas aos dividendos, juros e royalties do mesmo. $\mathrm{O}$ presente trabalho tem o objetivo de analisar os critérios para a determinação do significado desse termo nos acordos celebrados com base na Convenção Modelo da OCDE, examinando também os limites e implicações de sua definição para os Estados Contratantes.

A Introdução tem o objetivo de delimitar o escopo do objeto de estudo, bem como apresentar algumas prévias considerações didáticas sobre o direito tributário internacional, ramo no qual este estudo se insere. No Capítulo I, analisaremos a origem do termo beneficiário efetivo. $\mathrm{O}$ elemento central é a sua relação com os atributos do direito de propriedade no direito interno dos países de common law, onde este foi criado. Adicionalmente, realizaremos a comparação com o tratamento legal dessa expressão no direito interno dos países de civil law e, especificamente, no direito interno brasileiro.

O Capítulo II compreende o exame das regras de interpretação dos acordos internacionais contra a bitributação e de que maneira a construção de sentido de termos não definidos em seu texto é realizada. Para este fim, serão analisados os diversos instrumentos que compõe o contexto desses acordos, assim como a relação entre os demais instrumentos que podem auxiliar neste processo de exegese, demonstrando também as condições para o reenvio interpretativo do termo por meio de lei interna dos Estados Contratantes.

No Capítulo III, as diferentes formas e critérios para a interpretação do termo serão estudados. Será analisada a disciplina do tema na CM OCDE e Comentários, a sua relevância e alcance no combate ao treaty shopping e a jurisprudência internacional atual.

Ao final, apresentaremos uma síntese conclusiva do nosso estudo.

BENEFICIÁRIO. EFETIVO. ACORDOS. BITRIBUTAÇÃO. INTERNACIONAL 


\begin{abstract}
The concept of beneficial owner in the double tax treaties, although not expressly defined, is a requirement for the treaty entitlement of persons receiving income from dividends, interest and royalties. This study aims at analyzing the criteria for the definition of its meaning within the double tax treaties that adopt the OECD Model Convention, also examining the limits and implications of this concept to Contracting States.

The purpose of the Introduction is to define the scope of the object of study and, also, to present certain didactic considerations about international tax law, the area to which this work is related. In Chapter I, the origin of the term beneficial owner is analyzed. The main element therein is its relationship with the attributes of property law under the domestic laws of the common law countries, where it was created. Additionally, we will proceed the comparison with the legal treatment of this expression in the internal law of the civil law countries and, specifically, in the Brazilian law.

Chapter II deals with the analysis of the interpretation rules of the double tax treaties and on which way they act on the construction of the meaning of terms not defined on its text. For this purpose, the several instruments that constitute the context of the tax treaties will be analyzed, as well as the relation of the other instruments that may help in the interpretation process, demonstrating the requirements for the interpretative remittance of the term through domestic law of the Contracting States.

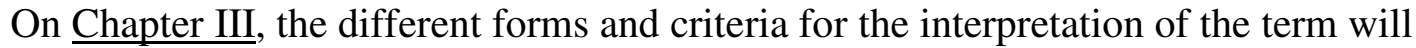
be examined. Also, we will analyze the treatment of the subject on OECD MC and Commentaries, its relevance and scope in the fight against treaty shopping and the current international jurisprudence.
\end{abstract}

At the end, we will present a conclusive synthesis of our study.

BENEFICIAL. OWNER.TAX. TREATIES. INTERNATIONAL. 


\section{INTRODUÇÃO}

\section{A. Considerações didáticas ${ }^{1}$}

\section{Acordos internacionais contra a bitributação}

O fenômeno da dupla ou bitributação ${ }^{2}$ provoca, por óbvio, um efeito prejudicial ao desenvolvimento econômico e aos investimentos internacionais entre os países, em razão da oneração das operações transnacionais ${ }^{3}$. Apesar de não existir, até hoje, um princípio internacionalmente aceito que a vede ${ }^{4}$, existe um consenso entre os Estados com relação à importância de se combater essa cumulação de pretensões tributárias impositivas pelos diferentes países ${ }^{5}$.

Assim, precisamente em razão da ausência de norma de direito internacional que proíba qualquer Estado de exercer sua soberania fiscal em tais situações ${ }^{6}$, i.e., envolvendo mais de um país, contanto que haja um elemento de conexão (genuine link) legítimo previsto em seu ordenamento jurídico, a sobreposição de competências tributárias resultará

\footnotetext{
${ }^{1} \mathrm{O}$ principal objetivo destas considerações didáticas é o de fornecer ao leitor uma visão panorâmica que abrange os principais problemas relacionados ao direito tributário internacional - notadamente a relativização da soberania fiscal, a sobreposição de competências tributárias e o fenômeno da dupla ou multi tributação jurídica e econômica - além de expor de forma geral a estrutura, importância e aplicação da Convenção Modelo da OCDE como base para os acordos internacionais contra a bitributação. Portanto, procura-se fornecer ao leitor um apanhado geral sobre os temas a serem tratados neste estudo sem, contudo, quaisquer pretensões de nos aprofundarmos sobre esses assuntos ora referidos.

${ }^{2}$ TÔRRES utiliza o termo pluritributação para se referir às situações em que diversas competências tributárias dos Estados são sobrepostas, implicando na tributação da mesma renda por mais de dois países. Cf. TÔRRES, Heleno Taveira. Dupla (Múltipla) tributação internacional. Rendas de empresas: 'dupla tributação jurídica internacional' e 'dupla tributação econômica internacional'. Revista de Direito Tributário, São Paulo, n. 65, p. 68, 1995.

${ }^{3}$ HUCK, Hermes Marcelo. Evasão e elisão: rotas nacionais e internacionais do planejamento tributário. São Paulo: Saraiva, 1997. p. 232.

${ }^{4}$ Cf. SCHOUERI, Luís Eduardo. Planejamento fiscal através de acordos de bitributação: treaty shopping. São Paulo: Ed. Revista dos Tribunais, 1995. p. 19.

${ }^{5} \mathrm{Cf}$. Comentários da OCDE à Convenção Modelo, Introdução, item 1. No original: International juridical double taxation can be generally defined as the imposition of comparable taxes in two (or more) States on the same taxpayer in respect of the same subject matter and for identical periods. Its harmful effects on the exchange of goods and services and movements of capital, technology and persons are so well known that it is scarcely necessary to stress the importance of removing the obstacles that double taxation presents to the development of economic relations between countries. (Cf. RAAD, Kees van. Materials on international \& EC tax law: 2009-2010. Selected and edited by Kees van Raad. $8^{\text {th }}$ ed. The Hague: IBFD/ITC, 2009. v. 1, p. 47).

${ }^{6}$ Cf. VOGEL, Klaus. Klaus Vogel on double taxation conventions: a commentary to the OECD, UN and US model conventions for the avoidance of double taxation of income and capital with particular reference to German treaty practice. 3rd ed. Boston: Kluwer Law International, 1997. p. 11.
} 
em um mesmo rendimento ser tributado pelo mesmo tributo duas vezes, por dois Estados, em relação a um mesmo contribuinte, num mesmo espaço de tempo. Este fenômeno é conhecido como dupla tributação jurídica, e se diferenciando da chamada dupla tributação econômica, na medida em que a última consiste na tributação de um mesmo rendimento, mas de contribuintes distintos ${ }^{7}$.

Em regra, a dupla ou bitributação jurídica ocorre quando dois países (Estado da Fonte e Estado da Residência) enxergam de forma distinta uma mesma situação internacional, ensejando uma diferente caracterização da renda ${ }^{8}$, da residência seu sujeito recebedor ${ }^{9}$ ou da origem de sua fonte de produção ${ }^{10}$, em função de critérios distintos para sua tributação ${ }^{11}$ e, assim, originando pretensões fiscais cumulativas de ambos os países.

Desta forma, visando exatamente evitar estes tipos de situações é que ganham importância os acordos internacionais contra a bitributação ${ }^{12}$. Estes acordos consistem em

${ }^{7}$ Cf. ROTHMANN, Gerd W. Bitributação internacional. In: Temas fundamentais do direito tributário atual. Belém: CEJUP, 1983. p. 123-146; HOORN JR., J. van. Bitributação: uma tentativa de definição. In: MACHADO, Brandão (Coord.). Direito tributário (estudos em homenagem ao Prof. Ruy Barbosa Nogueira). São Paulo, Saraiva, 1994. p. 305-314; VOGEL, Klaus. op. cit., p. 2.

${ }^{8}$ Este conflito é conhecido coloquialmente como conflito residência-fonte, e ocorre quando o Estado da Fonte classifica a renda como de um determinado tipo (por ex., prestação de serviços) e o Estado da Residência classifica a mesma renda como outro item (por ex., royalties). Esse exemplo ilustra precisamente o célebre caso Pierre Boulez, maestro francês residente na Alemanha, que foi contratado por empresa norte-americana para gravar uma série de concertos nos EUA. À época, os EUA (Estado da Fonte) classificaram esses rendimentos como renda decorrente da prestação de serviços, ao passo que a Alemanha (Estado da Residência) entendeu tratar-se de royalites pelos direitos autorais musicais. Uma vez que a Alemanha tributa os royalties de recebidos por seus residentes e os EUA tributam os serviços prestados por não-residentes em seu território, estabeleceu-se o conflito residência-fonte. Cf. Boulez v. Commissioner, 83 T.C. 584.

${ }^{9}$ Este conflito é conhecido coloquialmente como conflito residência-residência, e ocorre quando dois Estados entendem ser o contribuinte residente em seus respectivos territórios. Um exemplo ocorre quando uma sociedade tem sede no território de um Estado e possui administração efetiva em outro. Se o primeiro utilizar o local da sede ou de constituição da sociedade como critério de residência para fins fiscais, irá tributar os rendimentos desta sociedade. Se o outro Estado utilizar o critério de direção ou administração efetiva para determinar a residência de seus contribuintes, também irá tributar essa sociedade. Haverá, portanto, a tributação por força de dois Estados de Residência. Cf. RAAD, Kees van. Dual residence and 1977 OECD model treaty article 4(1), second sentence, ineuropean taxation. Amsterdam: IBFD, Jan. 1999. p. 241-246.

${ }^{10}$ Este conflito é conhecido coloquialmente como conflito fonte-fonte, e ocorre quando uma empresa com dupla residência em dois Estados (Estado A e Estado B) distintos paga rendimentos para um terceiro Estado (Estado C). Como os Estados A e B tratam a sociedade como residente, estarão aptos a considerar que a fonte do rendimento está situada em seus respectivos territórios, ensejando a tributação de ambos como Estado da Fonte. Cf. JONES, John Avery F. et al. Tax treaty problems relating to source. European Taxation, Amsterdam, IBFD, p. 78-93.

${ }^{11}$ JONES, John F. Avery. Credit and exemption under tax treaties in case of differing income characterization. Diritto e Pratica Tributaria, v. 77, n. 3, p. 754, 1996.

${ }^{12}$ Embora se privilegie neste estudo o uso do termo acordo, não deixamos de aceitar e inclusive utilizar como sinônimas outras denominações utilizadas pela doutrina, tais como tratado e convenção. Alguns doutrinadores, entre eles o professor ROTHMANN, destacam que o termo acordo é mais usado para designar a contratação bilateral entre países, enquanto o termo convenção seria mais apropriado para se referir às contratações multilaterais contra bitributação. Todavia, utilizaremos todos esses termos como sinônimos, por entendermos que não ocasionam prejuízos ou confusões terminológicas para este trabalho (Cf. ROTHMANN, Gerd W. Interpretação e aplicação dos acordos internacionais contra a bitributação. 1978. Tese (Doutorado) - Faculdade de Direito da Universidade de São Paulo, 1978. p. 15). 
instrumentos de direito internacional público, de caráter bilateral, por meio dos quais os países delimitam a sua soberania fiscal em relação a situações de caráter internacional, por meio da repartição de competências em matéria tributária e com o objetivo de evitar a bitributação da renda e combater a evasão fiscal ${ }^{13}$. Além disso, possuem também como objetivo promover o investimento estrangeiro, reduzir entraves ao comércio internacional, prevenir eventuais discriminações de nacionais, incentivar a troca de informações fiscais ${ }^{14}$, dar maior segurança jurídica aos contribuintes ${ }^{15}$ e evitar a dupla não-tributação ${ }^{16}$.

A crescente e sedimentada importância dos acordos contra a bitributação acentuouse a partir da segunda metade do século XX, em virtude do processo de globalização e a conseqüente intensificação da internacionalização da economia, desenvolvimento tecnológico e incremento no fluxo transnacional de bens, pessoas, serviços e capitais, de forma geral ${ }^{17}$. No ano de 2002 estimou-se que existissem mais de 2.500 acordos contra a bitributação em vigor, sendo provável que, após uma década, esse número deve ter aumentado ${ }^{18}$.

Convém reiterar que os acordos internacionais contra a bitributação não são normas de conflito, como aquelas de direito internacional privado, que definem a prevalência de uma lei sobre outra ${ }^{19}$. São, juridicamente, regras de limitação da eficácia da lei fiscal dos Estados Contratantes $^{20}$, visto que apenas impõem regras de distribuição, as quais determinam a repartição de competências em matéria tributária, balanceando a capacidade tributária ativa desses países ${ }^{21}$.

Por serem classificados como normas de direito internacional público, sujeitam-se a um regime próprio. Apesar de inexistir regra geral aplicável em nível internacional quanto ao processo formal de elaboração dos $\operatorname{acordos}^{22}$, no Brasil é necessário que observem rito

${ }^{13}$ Cf. ARNOLD, Brian J. Tax treaties and tax avoidance: the 2003 revisions to the commentary to the OECD Model. Bulletin for International Taxation, Amsterdam, p. 244-260, June 2004.

${ }^{14}$ PROKISCH, Rainer. A intepretação dos tratados de dupla tributação. Fisco, n. 68, p. 26, 1994.

${ }^{15} \mathrm{Cf}$. VASCONCELLOS, Roberto França. Aspectos econômicos dos tratados internacionais em matéria tributária. Revista de Direito Tributário Internacional, São Paulo, n. 1, p. 147 e ss., 2005.

${ }^{16}$ Cf. KIENBERGER, S. Avoidance of double (non-)taxation and art. 23 A and B paragraph 1 OECD MC. In: Conflicts of qualification in tax treaty law. Wien: Linde, 2007. p. 309-322.

${ }^{17}$ Cf. BAKER, Philip. A tributação internacional no século XXI. Direito Tributário Atual, São Paulo, n. 19, p. 41, 2005.

${ }^{18}$ Cf. ARNOLD, Brian J. et al. Summary of the Proceedings of an Invitational Seminar on Tax Treaties in the 21st Century. Bulletin - Tax Treaty Monitor, Amsterdam, June 2002. p. 233.

${ }^{19}$ Sobre as normas de conflito do direito internacional privado vide DOLINGER, Jacob. Direito internacional privado. 6. ed. Rio de Janeiro: Renovar, 2001. p. 25.

${ }^{20}$ Cf. SCHOUERI, Luís Eduardo. Tratados e convenções internacionais sobre tributação. Direito Tributário Atual, São Paulo, n. 17, p. 35, 2003.

${ }^{21}$ Cf. SILVEIRA, Rodrigo Maitto da. Aplicação de tratados internacionais contra a bitributação: qualificação de partnership joint ventures. São Paulo: Quartier Latin, 2006. p. 75. (Série Doutrina Tributária v. 1).

${ }^{22}$ Cf. BORGES, Antônio de Moura. Convenções sobre dupla tributação internacional. Teresina: EDIFPI; São Paulo: IBDT, 1992. p. 109. 
especial caracterizado pelas etapas de negociação, celebração ou execução, ratificação e aprovação pelo congresso nacional, para produção de efeitos no ordenamento jurídico interno $^{23}$. A norma de direito internacional que regula a criação, interpretação e aplicação dos tratados internacionais em geral e, por óbvio, também aplicável aos acordos internacionais contra a bitributação, é a Convenção de Viena sobre o Direito dos Tratados (CVDT) ${ }^{24}$.

Apesar de grande debate na doutrina ${ }^{25}$ e na jurisprudência brasileira ${ }^{26}$, pode-se afirmar que no Brasil prevalece entendimento de que os acordos que versem sobre normas tributárias têm supremacia em relação às leis fiscais internas ${ }^{27}$. A confirmação desse entendimento pode ser extraída do Artigo 98 do Código Tributário Nacional (CTN) ${ }^{28}$, que consagra o primado do direito internacional de prevalência dos tratados sobre a lei interna. Ademais, esse argumento é extraído dos princípios de direito internacional público consagrados na CVDT, sobretudo os Artigos $26^{29}$ e $27^{30}$, que consagram a prevalência dos tratados e, portanto, dos acordos contra a bitributação em face de legislação interna.

Por fim, é importante ressaltar que, em razão do caráter bilateral dos acordos contra a bitributação, as limitações por eles impostas apenas produzem efeitos entre os países signatários. Em outras palavras, os acordos desta natureza não são dotados de força normativa para abranger todas as relações jurídicas originadas do direito interno dos Estados Contratantes, mas apenas aquelas específicas às quais se aplicam ${ }^{31}$.

${ }^{23}$ Cf. GODOI, Marciano Seabra de. Os tratados ou convenções internacionais para evitar a dupla tributação e sua hierarquia normativa no direito brasileiro: In: SCHOUERI, Luis Eduardo (Coord.). Direito Tributário (Homenagem a Alcides Jorge Costa). São Paulo: Quartier Latin, 2003.v. 2, p. 975-1008; XAVIER, Alberto. Direito internacional tributário do Brasil. 6. ed. Rio de Janeiro: Forense, 2004. p. 105; MEDEIROS, Antônio Paulo Cachapuz de. O poder de celebrar tratados: competência dos poderes constituídos para a celebração de tratados, à luz do direito internacional, do direito comparado e do direito constitucional brasileiro. Porto Alegre: Sérgio Antonio Fabris, 1995. p. 202-204.

${ }^{24}$ Convenção de Viena sobre o Direito dos Tratados, celebrada em 23 de maio de 1969, ratificada pelo Brasil por meio do Decreto $\mathrm{n}^{\circ} 7.030$, de 14 de dezembro de 2009.

${ }^{25}$ Para uma síntese sobre a discussão vide ROCHA, Sérgio André. Treaty override no ordenamento jurídico brasileiro. São Paulo: Quartier Latin, 2007. p. 12 e ss.

${ }^{26}$ BRASIL, Supremo Tribunal Federal, Pleno. RE 90.824-SP, Rel. Min. Moreira Alves. J. 25/06/1980 confirmou a supremacia dos tratados em face de lei interna, contrariando a decisão no RE 80.004 anterior.

${ }^{27}$ Nesse sentido XAVIER, Alberto. op. cit., p. 108-109; ROTHMANN, Gerd W. Interpretação e aplicação dos acordos internacionais contra a bitributação, cit., p. 27-33.

${ }^{28}$ Art. 98 Os tratados e as convenções internacionais revogam ou modificam a legislação tributária interna, $e$ serão observados pela que lhes sobrevenha.

${ }^{29}$ Artigo 26. Todo tratado em vigor obriga as partes e deve ser cumprido por elas de boa fé. Cf. Convenção de Viena sobre o Direito dos Tratados, celebrada em 23 de maio de 1969.

${ }^{30}$ Artigo 27. Uma parte não pode invocar as disposições de seu direito interno para justificar o inadimplemento de um tratado. Cf. Convenção de Viena sobre o Direito dos Tratados, celebrada em 23 de maio de 1969.

${ }^{31}$ Cf. SCHOUERI, Luís Eduardo. Direito tributário internacional: qualificação e substituição - tributação, no Brasil, de rendimentos provenientes de sociedade de pessoas residente na Alemanha. Revista Dialética de Direito Tributário, São Paulo, n. 54, p. 125-139, 2000. 


\section{Direito tributário internacional no Brasil: considerações gerais}

No que diz respeito ao Brasil, o país adota - assim como a grande maioria dos sistemas tributários modernos - a tributação da renda baseando-se no princípio da universalidade $^{32}$, utilizando os elementos de conexão da fonte e da residência, mas não o da nacionalidade ${ }^{33}$. Assim, tributa a renda das pessoas físicas e jurídicas residentes no Brasil independentemente do local em que foram originadas e produzidas, bem como tributa os rendimentos de não-residentes produzidos por fonte brasileira (seja pela cumulação de fonte de pagamento e produção da renda, ou pela presença de apenas uma destas fontes) ${ }^{34}$.

Ademais, existem na lei interna brasileira mecanismos unilaterais para evitar a bitributação da renda. A regra geral é o reconhecimento do crédito do imposto de renda pago no exterior, por parte dos residentes em território nacional, para utilização no cômputo do imposto de renda a ser pago no Brasil ${ }^{35}$, limitado ao imposto total devido (i.e., o Brasil não concede crédito a maior ao contribuinte se a tributação no exterior for superior à tributação brasileira sobre a mesma renda).

Com relação à política de acordos internacionais contra a bitributação é importante ressaltar que o Brasil possui um modesto número de acordos celebrados ( 29 em plena vigência e eficácia ${ }^{36}$ ) quando comparado com países como Estados Unidos (quase 70

\footnotetext{
${ }^{32} \mathrm{O}$ princípio da universalidade da tributação da renda para as pessoas jurídicas foi instituído pelo artigo 25 da Lei $\mathrm{n}^{\circ}$ 9.249/1995 (produzindo efeitos a partir de $1^{\text {o }}$ de janeiro de 1996). Antes dessa data, ao contrário das pessoas físicas (sujeitas à tributação da renda em bases universais desde 1988 por força do art. $3^{\circ}$, parágrafo $4^{\circ}$ da Lei $n^{\circ} 7.713 / 1988$ ), as pessoas jurídicas sujeitavam-se à tributação em bases territoriais. Cf. XAVIER, Alberto. op. cit., p. 427 e ss.

${ }^{33} \mathrm{O}$ elemento de conexão da nacionalidade é utilizado pelos Estados Unidos e pelas Filipinas, para tributar a renda de seus nacionais, independentemente de serem residentes nestes países.

${ }^{34}$ SCHOUERI, Luís Eduardo. Princípios no direito tributário internacional: territorialidade, fonte e universalidade. In: FERRAZ, Roberto Catelano Botelho (Org.). Princípios e limites da tributação. 1. ed. São Paulo, Quartier Latin, 2005. v. 1, p. 321-374.

${ }^{35} \mathrm{O}$ direito ao crédito do imposto de renda pago no exterior é garantido para todas as pessoas jurídicas residentes no Brasil, nos termos do artigo 26 da Lei ${ }^{\circ}$ 9.249, de 26 de dezembro de 1995 e artigo 15 da Lei n 9.430 , de 27 de janeiro de 1996. Para as pessoas físicas, o crédito só será concedido se houver reciprocidade no tratamento por parte do país de origem, isto é, se o país que tributou a renda da pessoa física residente no Brasil também conceder medida unilateral para evitar a tributação de seu residente, se sua renda for tributada pelo Brasil, conforme dispõe o artigo $5^{\circ}$ da Lei $n^{\circ} 4.862$, de 29 de novembro de 1965.

${ }^{36}$ Os países com os quais o Brasil celebrou acordos internacionais contra a bitributação e que estão atualmente em vigor e em eficácia no sistema jurídico brasileiro são: África do Sul, Argentina, Áustria, Bélgica, Canadá, Chile, China, Coréia do Sul, Dinamarca, Equador, Eslováquia, Espanha, Filipinas, Finlândia, França, Holanda, Hungria, Índia, Israel, Itália, Japão, Luxemburgo, México, Noruega, Peru, Portugal, República Tcheca, Suécia e Ucrânia. Os acordos celebrados com a Venezuela e com a Rússia estão pendentes de aprovação pelo Congresso Nacional, apesar de já assinados. O acordo celebrado com o Paraguai, apesar de já ter sido aprovado pelo Congresso Nacional, ainda não foi objeto de Decreto Presidencial. Finalmente, o acordo celebrado com a Alemanha foi denunciado e deixou de produzir efeitos após 31.12.2006 (cf. Ato Declaratório SRF no 72, de 22 de dezembro de 2005. Vide, sobre o tema, ROTHMANN, Gerd W. A
} 
acordos), Holanda (cerca de 100 acordos) e Inglaterra (mais de 100 acordos). Talvez isso seja reflexo do recente histórico brasileiro, que se iniciou com a celebração deste tipo de acordos pela primeira vez em meados da década de $1960^{37}$. Convém apontar, ademais, que o Brasil não possui acordos com países como Estados Unidos ${ }^{38}$ e Inglaterra.

O Brasil adota, de forma geral, a Convenção Modelo da OCDE (CM OCDE) na celebração de seus acordos, seguindo a versão do modelo vigente à época da assinatura ${ }^{39}$, com algumas pequenas modificações em razão de o Brasil ser, predominantemente, um país importador de capital (na maior parte das vezes figurando como Estado da Fonte) e a CM OCDE ser estruturada para países exportadores de capital (normalmente o Estado da Residência), o que implica em diferenças na forma pela qual estes dois tipos de países tributam os rendimentos transnacionais ${ }^{40}$.

Por fim, é importante mencionar a particularidade adotada pelo Brasil na negociação de seus acordos contra a bitributação: a exigência das cláusulas de matching credit (crédito presumido) ${ }^{41}$ e tax sparing (crédito fictício) ${ }^{42}$. Essas cláusulas são normalmente utilizadas e exigidas em bases negociais por países não desenvolvidos e em desenvolvimento quando celebram acordos com países desenvolvidos, uma vez que são

denúncia do acordo de bitributação Brasil-Alemanha e suas conseqüências.In: ROCHA, Valdir de Oliveira (Coord.). Grandes questões atuais do direito tributário. São Paulo: Dialética, 2005. v. 9).

${ }^{37}$ Para uma análise histórica e comparativa dos acordos contra a bitributação celebrados pelo Brasil vide: SCHOUERI, Luís Eduardo. Contribuição à história dos acordos de bitributação: a experiência brasileira. Direito Tributário Atual, São Paulo, n. 22, p. 267-287, 2008.

${ }^{38}$ Para estudo sobre os motivos e perspectivas envolvendo a ausência de acordo contra a bitributação entre Brasil e Estados Unidos vide David H. Rosenbloom e Daniel Hora do Paço, Thoughts on the Brazil-U.S. Tax Treaty Negotiations, 56 Tax Notes International 517, 16 Nov. 2009; TAVOLARO, Agostinho Toffoli. Tratado Brasil/Estados Unidos para evitar a dupla tributação. Revista de Direito Tributário Internacional, São Paulo, v. 15, 2010.

${ }^{39}$ XAVIER, Alberto. op. cit., p. 103.

${ }^{40}$ Dentre as diferenças que mais nos chamam a atenção está a adoção do Artigo 21 (Outros Rendimentos) com base na Convenção Modelo da ONU (que permite a tributação cumulativa do Estado da Fonte e da Residência em relação aos rendimentos não enquadrados nos artigos anteriores do acordo), e não da OCDE (que estabelece a competência tributária exclusiva do Estado da Residência na tributação dos outros rendimentos), em vários acordos brasileiros.

${ }^{41} \mathrm{O}$ matching credit decorre da concessão de um crédito mais elevado do que aquele incidente na tributação pelo Estado da Fonte comparado com o crédito decorrente de sua lei interna. É, assim, um crédito de imposto a maior reconhecido pelo Estado da Residência. Esse dispositivo pode ser encontrado no acordo celebrado entre Brasil e Holanda (Decreto no 355 de 1991), no artigo 23, parágrafo $4^{\circ}$, letra (a), em que há previsão para um crédito de $25 \%$ sobre os dividendos pagos a sociedade holandesa que detenha no mínimo $10 \%$ do capital votante de uma sociedade brasileira, não obstante o Brasil isentar a tributação de dividendos pagos por sociedade brasileira, nos termos do artigo 10 da Lei $\mathrm{n}^{\circ} 9.249$ de 1995 .

${ }^{42} \mathrm{O}$ tax sparing decorre da concessão de um crédito do imposto que teria sido pago na fonte, mas que foi desonerado por medida unilateral, por parte do Estado da Residência. É, portanto, um crédito sobre imposto não pago, reconhecido pelo Estado da Residência. Esse dispositivo pode ser encontrado no acordo celebrado entre Brasil e Japão (Decreto n ${ }^{\circ} 61.899$ de 1967), no artigo 22, letra (b), que expressamente prevê como o montante do imposto no Brasil, para fins de crédito no Japão, aquele que teria incidido se não existisse isenção ou redução por força de lei brasileira. 
incentivos fiscais para atrair maiores investimentos estrangeiros em seus territórios, como parte de uma política econômica internacional ${ }^{43}$.

\section{Treaty Shopping e planejamento tributário por meio de acordos internacionais contra a bitributação}

No atual cenário tributário internacional, entendemos que é imprescindível uma análise e reflexão cuidadosa dos contornos e limites do conceito de beneficiário efetivo no planejamento tributário estruturado por meio de acordos internacionais contra a bitributação. Isso se mostra importante para que, de um lado, não se retorne ao formalismo excessivo marcado pela liberdade ampla e irrestrita do contribuinte diante de Estado Social Democrático de Direito (limitado pelo princípio da solidariedade fiscal ${ }^{44}$ ) e, de outro lado, não se consagre e incentive o atual fenômeno de Macarthismo elisivo ${ }^{45}$ que muitas administrações tributárias visam implementar em suas políticas fiscais, transformando a legítima economia legal de tributos em verdadeira caça às bruxas, que implica em clara violação aos direitos fundamentais do contribuinte em organizar livremente, dentro dos limites da lei, seus atos e negócios jurídicos.

Em um mundo pós-globalizado, a atração e concorrência internacional por investimentos estrangeiros são de suma importância para o crescimento e desenvolvimento econômico dos Estados - aprimorando novas tecnologias, desenvolvendo o parque industrial, gerando novos empregos, aumentando a demanda comercial e a arrecadação

\footnotetext{
${ }^{43}$ Cf. DORNELLES, Francisco Oswaldo Neves. Acordos para eliminar a dupla tributação da renda. Revista de Direito Tributário, São Paulo, n. 83, p. 251-257, jan./mar. 1978.

${ }^{44}$ CAMPOS, Diogo Leite de. Sistema tributário no Estado dos Cidadãos. Coimbra, Almedina, 2006. p. 78-79.

${ }^{45} \mathrm{O}$ neologismo por nós criado em trabalho anterior para demonstrar o atual combate extremado e desproporcional das autoridades fiscais em diversos países se baseia no fenômeno conhecido como Macarthismo (em inglês, McCarthyism), que é o termo utilizado para descrever um período de intensa patrulha anticomunista, perseguição política e desrespeito aos direitos civis nos Estados Unidos que durou do fim da década de 1940 até meados da década de 1950. Foi uma época em que o medo do Comunismo e da sua influência em instituições estadunidenses tornou-se exacerbado, juntamente ao medo de ações de espionagem promovidas pela União Soviética. Originalmente, o termo foi cunhado para criticar as ações do senador norte-americano Joseph McCarthy. O Macarthismo realizou o que alguns chamam de caça às bruxas (witch-hunt) na área cultural, atingindo atores, diretores e roteiristas que, durante a guerra, manifestaram-se a favor da aliança com a extinta União Soviética e, depois, a favor de medidas pacificadoras para evitar nova guerra. Cf. CASTRO, Leonardo Freitas de Moraes e. Análise da aplicação da teoria do substance over form aos planejamentos tributários no Brasil. Revista de Direito Tributário da APET, São Paulo, n. 22, p. 35, 2009.
} 
tributária etc. -, refletindo-se também na esfera tributária ${ }^{46}$, por meio de incentivos fiscais gerais, isenções condicionais, reduções de alíquotas, créditos presumidos de impostos, diferimento na tributação etc. Essa constatação foi, inclusive, objeto de estudo específico consubstanciado no relatório da OCDE intitulado Concorrência Fiscal Prejudicial ${ }^{47}$.

Com o intuito de exclusiva ou preponderantemente obter vantagens fiscais e, assim, reduzir o impacto tributário em seus negócios, alguns contribuintes que exercem atividades econômicas transnacionais muitas vezes estruturam suas operações fazendo uso dos benefícios previstos em acordos internacionais contra a bitributação de diversos Estados.

Uma vez que esses acordos são verdadeiros contratos bilaterais celebrados entre Estados soberanos por meio de extensos e complexos procedimentos de negociação caracterizados por concessões mútuas e específicas, que variam conforme a situação econômica, política, social e diplomática de cada Estado Contratante eles se baseiam, como regra geral, no princípio da reciprocidade. Por essa razão, não são extensíveis a terceiros Estados que, por não participarem do processo de negociação e não realizarem quaisquer concessões, não fazem parte desse acordo.

Todavia, por diversos motivos, tais como falhas na redação dos acordos, limitações de direito interno ou objetivos e fins secundários das partes, podem permitir que contribuintes residentes em um terceiro Estados se beneficiem das disposições do tratado, ainda que, originalmente, eles não estivessem inseridos no escopo pessoal do acordo contra a bitributação ${ }^{48}$.

O nome dado a essa prática de utilização indevida dos benefícios dos acordos por pessoas para as quais tais benefícios não estariam disponíveis diretamente é conhecida como treaty shopping ${ }^{49}$. Na definição de SCHOUERI ocorre o treaty shopping quando

\footnotetext{
${ }^{46}$ Sobre o tema envolvendo o planejamento tributário internacional e os regimes preferenciais de tributação, vide: HUCK, Hermes Marcelo. op. cit.

${ }^{47}$ Esse relatório realizou detida análise dos regimes fiscais prejudiciais utilizados em âmbito internacional, pelos diversos Estados, consignando que (...) a globalização tem gerado um efeito positivo no desenvolvimento dos sistemas fiscais. Entretanto, a globalização tem também gerado um efeito negativo de permitir o acesso a novos meios pelos quais as empresas e os indivíduos podem minimizar e evitar tributos e nos quais os países podem explorar essas novas oportunidades desenvolvendo políticas fiscais visando primariamente à atração de capitais financeiros ou outros tipos de capitais móveis. No original: (...) globalization has had a positive effect on the development of tax systems. Globalization has, however, also had the negative effects of opening up new ways by which companies and individuals can minimize and avoid taxes and in which countries can exploit these new opportunities by developing tax policies aimed primarily at diverting financial and other geographically mobile capital. Cf. OECD. Harmful Tax Competition - an emerging global issue. Paris: OECD, 1998. parágrafo 76.

${ }^{48}$ SCHOUERI, Luís Eduardo. Planejamento fiscal através de acordos de bitributação: treaty shopping, cit., p. 20.

${ }^{49}$ IBFD. International Tax Glossary. Ed. Susan M. Lyons. 2. ed. Amsterdam, 1992. p. 260.
} 
alguém, através da interposição de uma pessoa, obtém a proteção de um acordo de bitributação que, de outro modo, não seria devida ${ }^{50}$.

A doutrina ${ }^{51}$ entende que deve haver um requisito essencial para tal caracterização, qual seja, que a interposição de um terceiro beneficiário do acordo de bitributação tenha única e exclusivamente o intuito de obter vantagens fiscais decorrente deste acordo.

Há também outro conceito na doutrina internacional, bastante utilizado, que seria o de abuso dos tratados ou treaty abuse ${ }^{52}$. Conceitualmente é bastante semelhante ao treaty shopping, por envolver a utilização abusiva ou não-desejada das disposições dos tratados (unintended treaty benefits) e, pragmaticamente, geram resultados semelhantes e difíceis de serem diferenciados entre si. Não existe consenso doutrinário sobre a definição e diferenças entre estes termos. Tais conceitos serão abordados de forma específica no Capítulo III.

Vale ressaltar que, para alguns autores como $\operatorname{ROSENBLOOM}^{53}$, ambas as expressões merecem críticas: abuso de tratados seria um termo fortemente carregado, ao passo que treaty shopping seria uma expressão enganosa, por pressupor esforço premeditado do contribuinte. Haveria, assim, uma carga pejorativa em tais expressões, apesar de que, para nós, por tais expressões já estarem consagradas no direito tributário internacional, entendemos pertinentes seu uso, desde que preenchidos os requisitos para caracterizá-las.

O termo treaty shopping nasceu nos Estados Unidos ${ }^{54}$, tendo sido mencionado no U.S. Congressional Hearings on Offshore Tax Havens nos anos $70^{55}$, e deriva do termo

\footnotetext{
${ }^{50}$ SCHOUERI, Luís Eduardo. Planejamento fiscal através de acordos de bitributação: treaty shopping, cit., p. 20-21.

${ }^{51}$ [treaty shopping occurs] occurs when "tax planners (...) establish corporate vehicles in third countries to take advantage of the benefits of a treaty between the third country and the country in which income would be earned. Cf. GUSTAFSON, Charles; PERONI, Robert; PUGH, Richard. Taxation of international transactions: materials, texts and problems. 3rd ed. Thompson, 2007. p. 221. (American Casebook Series, West).

${ }^{52} \mathrm{O}$ treaty abuse é assim definido pela doutrina: Use that has the sole (predominant) intention to avoid the tax of either or both of the contracting states and that defeats the fundamental and enduring expectations and policy objectives shared by both states and therewith the purpose of the treaty in a broad sense (WEEGHEL, Stef van. The improper use of tax treaties: with particular reference to the Netherlands and the United States. London: Kluwer Law International, 1998. p. 258. (Series of International Taxation n. 19). ${ }^{53}$ ROSENBLOOM, David H. Tax treaty abuse: policies and issues. Law \& Policy International Business, v. 15, p. 763-764, 1983.

${ }^{54}$ AVI-YONAH; Reuven; PANAYI, Christiana HJI. Rethinking treaty shopping: lessons for the European Union 2, Public Law and Legal Theory Working Paper Series, Working Paper, n. 182, p. 2, Jan. 2010.

${ }^{55}$ The Use of Offshore Tax Havens for the Purpose of Evading Income Taxes: Hearing before the Subcomm. on Oversight of the H. Comm. on Ways and Means, 96th Cong. 284 (1979) (statement of David H. Rosenbloom, Int. Tax Counsel, Dep't of the Treasury); ROSENBLOOM, David H. op. cit., p. 763-766.
} 
forum shopping, isto é, quando uma parte tenta comprar (shop) uma jurisdição mais favorável para seu caso ou situação ${ }^{56}$.

Para a caracterização deste fenômeno, a estrutura negocial pode ser bilateral ou triangular, sendo mais comuns os casos de uso de empresas-canais (conduit companies) e empresas trampolins (stepping stone companies), que consistem em sociedades intermediárias (holding companies $^{57}$ ) interpostas entre o Estado da Fonte e o terceiro Estado do investidor. A diferença básica entre essas duas estruturas reside no fato de que, na primeira (canalização) a empresa interposta não está sujeita a tributação em sua sede, ao passo que na segunda (trampolim) esta está sujeita a tributação, razão que justifica a transferência dos benefícios do acordo de bitributação, como despesas, erodindo a base de cálculo tributável ${ }^{58}$.

AVI-YONAH et al. aponta três requisitos básicos para se identificar estruturas de treaty shopping: (i) o beneficiário efetivo da entidade que pratica o treaty shopping não é residente no Estado em que ela foi constituída; (ii) a entidade interposta possui mínima ou nenhuma atividade econômica na jurisdição em que foi constituída; e (iii) a renda auferida pela entidade interposta está sujeita a baixa ou nenhuma tributação em seu país de residência ${ }^{59}$.

Apesar de ser de fácil definição teórica, a prática do treaty shopping é extremamente difícil de ser identificada nas complexas estruturas internacionais modernas, sendo tarefa árdua determinar quando um contribuinte está utilizando de forma indevida ou abusiva os benefícios de um acordo contra a bitributação em situações envolvendo grandes grupos econômicos em diversas jurisdições.

Assim sendo, para conter o treaty shopping os Estados utilizam-se de medidas internas (atos normativos domésticos unilaterais ${ }^{60}$ ) e de medidas internacionais bilaterais

\footnotetext{
${ }^{56}$ HELMUT, Becker; WURM, Felix J. Survey. In: Treaty Shopping: an emerging tax issue and its present status in various countries 1, 1988, p. 2.

${ }^{57}$ Uma holding company é geralmente uma sociedade de capital, uma sociedade anônima (...), concebida como um centro financeiro apto para gerir o capital acionário controlado ou operar em setores econômicos mediante as entidades controladas, numa estratégia unitária, figurando quase sempre, como 'controladora' do grupo de sociedades. Cf. TÔRRES, Heleno Taveira. Pluritributação internacional sobre as rendas de empresas. 2. ed. São Paulo: Ed. Revista dos Tribunais, 2001. p. 266.

${ }^{58}$ SCHOUERI, Luís Eduardo. Planejamento fiscal através de acordos de bitributação: treaty shopping, cit., p. 25.

${ }^{59}$ AVI-YONAH; Reuven; PANAYI, Christiana HJI. op. cit., p. 5.

${ }^{60}$ Por exemplo, as chamadas medidas gerais anti-abuso (General Anti-Abuse Rules - GAAR), usualmente baseadas no princípio da proibição da fraude à lei, abuso de forma ou prevalência da substância sobre a forma, abuso de direito, necessidade de propósito negocial e aplicação da interpretação econômica das normas tributárias. Para uma análise sobre essas medidas e sua aplicabilidade com o direito brasileiro vide: YAMASHITA, Douglas. Elisão e evasão de tributos - planejamento tributário: limites à luz do abuso de
} 
(cláusulas ou dispositivos nos próprios acordos de bitributação celebrados entre os Estados $^{61}$ ). Neste ponto concordamos integralmente com SCHOUERI sobre a inconveniência do tratamento interno unilateral para combate ao treaty shopping, sendo necessárias e recomendáveis medidas nos próprios acordos de bitributação para combater ou evitar tal fenômeno ${ }^{62}$.

Nesse sentido, partindo-se da premissa de que um acordo contra a bitributação implica em certa renúncia à soberania fiscal, por parte dos Estados Contratantes, ao possibilitar acesso de terceiros aos dispositivos veiculados pelos acordos, cria-se um desequilíbrio na relação entre os Estados Contratantes e uma vantagem indevida ao terceiro Estado, implicando em divisão inadequada das receitas tributárias entre os Estados Contratantes ${ }^{63}$.

Precisamente por esse motivo, o treaty shopping foi, durante décadas, considerado prejudicial para o desenvolvimento das atividades econômicas e relações internacionais entre os Estados Contratantes, uma vez que (i) viola a reciprocidade de um tratado e altera o equilíbrio das mútuas concessões nele consignadas entre os dois Estados Contratantes; (ii) permite que um terceiro Estado obtenha poder de tributar a renda mesmo na ausência de qualquer reivindicação substancial de aliança econômica; (iii) cria um desincentivo para os países negociarem acordos contra a bitributação; e (iv) a ausência de cooperação fiscal aumenta as oportunidades de evasão fiscal internacional ${ }^{64}$.

Ademais, é comum, na doutrina ${ }^{65}$, a classificação da utilização do termo beneficiário efetivo como uma das medidas de combate ao treaty shopping, ao lado das

direito e da fraude à lei. São Paulo: Lex, 2005; ROLIM, João Dácio. Normas antielisivas tributárias. São Paulo: Dialética, 2011; BIANCO, João Francisco, Planejamento tributário: estudo de casos e exame crítico da jurisprudência. In: YAMASHITA, Douglas (Coord). Planejamento tributário à luz da jurisprudência. São Paulo: Lex, 2007; BARRETO, Paulo Ayres. Elisão tributária: limites normativos. Tese (Livredocência) - Faculdade de Direito da Universidade de São Paulo, São Paulo, 2008.

${ }^{61}$ Para uma visão ampla sobre o tema, vide: DUFF, David G. Responses to treaty shopping: a comparative evaluation. In: LANG, Michael et al. (Ed.). Tax treaties: building bridges between law and economics. Amsterdam, IBFD, 2010. p. 75-102.

${ }^{62}$ SCHOUERI, Luís Eduardo. Planejamento fiscal através de acordos de bitributação: treaty shopping, cit., p. 140.

${ }^{63} \mathrm{Cf}$. OECD. Double Taxation Conventions and the use of conduit companies. In: ORGANISATION FOR ECONOMIC CO-OPERATION AND DEVELOPMENT. International Tax Avoidance and Evasion: four related studies. Paris: OECD, 1987. p. 90. (Issues of International Taxation, n. 1).

${ }^{64}$ AVI-YONAH; Reuven; PANAYI, Christiana HJI. op. cit., p. 5-7.

${ }^{65}$ BAMMENS, Niels; DE BROE, Luc. Treaty shopping and avoidance of abuse. In: LANG, Michael et al. (Ed.). Tax treaties: building bridges between law and economics. Amsterdam: IBFD, 2010. p. 52-74; AVIYONAH; Reuven; PANAYI, Christiana HJI. op. cit., p. 3-7; DUFF, David G. op. cit., p. 75-102; FRASER, Ross; OLIVER, J.D.B. Treaty shopping and beneficial ownership: indofood International Finance Limited v. JP Morgan Chase Bank, N.A., London Branch. British Tax Review, n. 4, p. 422-426, 2006; ARGINELLI, Paolo. The Royal Bank of Scotland case: more controversy on the interpretation of the term 'beneficial 
cláusulas de limitação de benefícios (cláusulas LOB), sob o argumento de que ambas as medidas utilizadas nos acordos internacionais contra a bitributação visam identificar a existência de uma mínima conexão entre o Estado da Residência e a pessoa que almeja usufruir das vantagens do acordo específico.

Entretanto, curiosamente, uma recente decisão proferida pela Suprema Corte da Índia no caso Union of India v. Azadi Bachao Andolan, negou a aplicação de uma cláusula implícita de combate ao treaty shopping no acordo contra a bitributação celebrado entre Índia e Ilhas Maurício, ao decidir que países em desenvolvimento, como a Índia, necessitam atrair investimentos estrangeiros e as oportunidades geradas por meio do treaty shopping podem ser fatores adicionais para atraí-los ${ }^{66}$. Nesse julgamento, a Suprema Corte enfatizou que essa prática pode ser, por vezes, considerada um incentivo à atração de investimentos estrangeiros e tecnologia, essenciais ao desenvolvimento econômico nacional, ao invés de uma prática prejudicial e abusiva (harmful and abusive practice).

Portanto, esta decisão trouxe uma nova discussão à comunidade tributária internacional, levantando a questão sobre o uso de um mal necessário que deve ser tolerado em países em desenvolvimento que desejem encorajar seu crescimento econômico por meio de atração de capital estrangeiro ${ }^{67}$. Essa posição, contudo, dependerá muito do país, variando de caso-a-caso, uma vez que o combate ao treaty shopping se revela uma decisão política, mais do que jurídica ${ }^{68} \mathrm{e}$, sem dúvida, se relaciona, ainda que indiretamente ${ }^{69}$, com o conceito de beneficiário efetivo nos acordos contra a bitributação.

owner'. In: RUSSO, Raffaele; FONTANA, Renata (Coords.). A decade of case law: essays in honour of the 10th anniversary of the Leiden Adv LLM in international tax law. Leiden: ITC/IBFD, 2008. p. 229-234.

${ }^{66}$ No original: Developing countries need foreign investments, and the treaty shopping opportunities can be an additional factor to attract them (Cf. Union of India v. Azadi Bachao Andolan, (2004) 10 S.C.C. 1).

${ }^{67}$ AVI-YONAH; Reuven; PANAYI, Christiana HJI. op. cit., p. 5.

${ }^{68}$ SCHOUERI, Luís Eduardo. Planejamento fiscal através de acordos de bitributação: treaty shopping, cit., p. 171.

${ }^{69}$ A importância e a relação entre o conceito de beneficiário efetivo variam na doutrina especializada. Cf: CATÃO, Marcos André Vinhas. A "cláusula de beneficiário efetivo" Limite de sua aplicação. In: TÔRRES, Heleno Taveira (Coord.). Direito internacional tributario aplicado. São Paulo, Quartier Latin, 2004. v. 2, p. 423-426; PASIN, João Bosco Coelho. O conceito de beneficiário efetivo nos convênios para evitar dupla imposição, como prevenção da elisão fiscal internacional. In: COLÓQUIO INTERNACIONAL DE DIREITO TRIBUTÁRIO, 5. Buenos Aires: La Ley, 2003. p. 439; ROLIM, João Dácio. A (des)necessidade de um conceito harmônico de "beneficiário efetivo" nos Acordos para evitar a dupla tributação: um caso brasileiro e o direito comparado. Revista Dialética de Direito Tributário, São Paulo, n. 179, p. 78-89, 2010; RUSSO, Antonio. Seminário Alumni Leiden de 2006: precedentes sobre interpretação dos tratados internacionais - caso indofood: conceito de beneficiário efetivo. Revista de Direito Tributário, São Paulo, n. 7, p. 217-221, 2007; TAVOLARO, Agostinho Toffoli. Beneficiário efetivo, cit., p. 9-21; TEIXEIRA, Alessandra Machado Brandão. O conceito de beneficiário efetivo nos convênios para evitar dupla imposição como prevenção da elisão fiscal internacional. In: COLÓQUIO INTERNACIONAL DE DIREITO TRIBUTÁRIO, 5. Buenos Aires: La Ley, 2003. p. 373 e ss.; BIANCO, João Francisco; NEWTON, Raquel. Beneficiário efetivo. Revista Direito Tributário Atual, São Paulo, n. 26, p. 253-270, 2011. 


\section{B. Delimitação do objeto de estudo e suas limitações}

1. Importância do conceito de beneficiário efetivo nos acordos internacionais contra a bitributação

O termo beneficiário efetivo incluído nos Artigos 10 (Dividendos), 11 (Juros) e 12 (Royalties) da CM OCDE é uma das condições necessárias para que as pessoas possam se beneficiar de algumas de suas disposições, isto é, fazer jus ao direito de usufruir alguns dos benefícios veiculados pelo acordo, no que se chama em inglês de treaty entitlement, compondo parte do escopo pessoal $^{70}$ (ou âmbito de aplicação $^{71}$ ) dos acordos especificamente para estes tipos de rendimento.

Além dos requisitos mínimos (ou gerais) exigidos para o direito de se invocar a aplicação das disposições de um acordo, previstos nos Artigos $1^{\circ}$ (Pessoas Visadas) e Artigo $4^{\circ}$ (Residente), os artigos específicos que tratam dos dividendos, juros e royalties exigem que, para a redução da tributação no Estado da Fonte (alíquota reduzida ou isenção), o beneficiário efetivo desses rendimentos seja residente no outro Estado Contratante (Estado da Residência).

Na hipótese de o beneficiário efetivo, nestes casos, não for um residente no outro Estado Contratante, o Estado da Fonte poderá tributar os rendimentos decorrentes de dividendos, juros e royalties de acordo com a sua lei interna - sem as limitações previstas no acordo contra a bitributação - majorando, assim, sua arrecadação tributária sobre esses pagamentos.

Uma vez que, nos casos de competência tributária cumulativa entre o Estado da Fonte e o Estado da Residência - como ocorre com os rendimentos dos Artigos 10, 11 e 12 da Convenção Modelo da OCDE -, o Estado da Residência é obrigado a conceder isenção (Artigo 23-A) ou crédito (Artigo 23-B) sobre tais rendimentos, como forma de eliminar a dupla ou bitributação da renda, a questão do beneficiário efetivo poderia parecer sem importância.

\footnotetext{
${ }^{70}$ Cf. SILVEIRA, Ricardo Maitto da. O escopo pessoal na aplicação dos acordos internacionais contra a bitributação. 2009. Dissertação (Mestrado). Faculdade de Direito da Universidade de São Paulo, 2009. p. 33 e ss.

${ }^{71}$ XAVIER, Alberto. op. cit., p. 155.
} 
Todavia, por trás da aparente simplicidade do mecanismo da prevenção da bitributação internacional reside uma complexa e divergente discussão sobre a interpretação dos termos dos acordos contra a bitributação, que são pressupostos, por óbvio, para a sua aplicação.

É nesse cenário que ocorre o conflito interpretativo entre o Estado da Fonte e da Residência, quando da aplicação de determinado artigo. Exemplo emblemático dessa discordância hermenêutica ocorre quando o Estado da Fonte, ao interpretar o conceito de beneficiário efetivo, entende que o destinatário da renda originada por uma fonte de produção sujeita à sua soberania fiscal não é residente no outro Estado Contratante e, portanto, a redução da carga fiscal incidente na fonte (prevista naquele acordo com o outro Estado Contratante) não deve ser aplicada, fazendo com que o Estado da Fonte exerça sua capacidade tributária plena, muitas vezes superior àquela prevista no acordo.

Uma vez que, o outro Estado (supostamente o Estado da Residência) pode, ao interpretar os termos do acordo, entender de forma diferente, isto é, concluindo que o destinatário dos rendimentos pagos por uma fonte localizada no Estado da Fonte é, em sua visão, residente em seu território, este Estado (Estado da Residência) pode se negar a conceder a isenção ou crédito, total ou parcialmente, sobre estes rendimentos, por discordar da interpretação dada pelo Estado da Fonte (i.e., tributação a maior na fonte).

A partir desse conflito interpretativo, o contribuinte localizado no outro Estado Contratante (supostamente o Estado da Residência) poderá, não raro, sofrer a bitributação de sua renda, em virtude da tributação pelo Estado da Fonte e, novamente, tributação pelo Estado da Residência.

Precisamente por este motivo, a determinação do conceito de beneficiário efetivo nos acordos contra a bitributação implica em compreender o sentido e alcance do poder de tributar do Estado da Fonte, em virtude de um acordo, para essas modalidades de rendimentos passivos. Uma vez que os rendimentos de dividendos, juros e royalties representam, em um cenário mundial pós-globalizado, informatizado e tecnológico, uma considerável parcela dos rendimentos empresariais das grandes corporações transnacionais, a importância dessa delimitação não é puramente acadêmica, mas de relevante aplicabilidade prática.

Assim, sobre a ótica dos contribuintes, é essencial verificar se, e em que limite, eles estarão aptos a usufruir dos benefícios dos acordos contra a bitributação, para, com isso, 
vislumbrar qual será o alcance máximo da carga tributária a que estarão submetidos quando optarem por investir seus recursos no exterior ${ }^{72}$ ou quando estiverem expostos a situações ou operações internacionais.

Ademais, sobre a perspectiva dos Estados Contratantes a delimitação dos contornos do conceito de beneficiário efetivo também possui importância fundamental. A escolha de um Estado soberano em celebrar um acordo contra a bitributação com outro país reflete um dos muitos aspectos de sua política fiscal, sobretudo em âmbito internacional, especificamente com relação à forma de incentivar os investimentos estrangeiros em seu território e, em geral, estimular as relações comerciais entre estes países. Como já dito, uma vez que a escolha em celebrar, voluntariamente, um acordo dessa natureza representa uma renúncia parcial ou total do Estado à sua soberania fiscal (i.e., ao poder de tributar), é natural assumir que o Estado apenas estará disposto a estender os benefícios dos acordos contra a bitributação para os contribuintes que estiverem compreendidos no seu âmbito subjetivo e, portanto, forem considerados como destinatários dessas convenções fiscais.

Para tanto, a clara definição do termo beneficiário efetivo é, especificamente para os rendimentos qualificados ${ }^{73}$ como dividendos, juros e royalties, imprescindível para a interpretação e aplicação minimamente harmônica e consensual destes instrumentos.

\section{Definição do tema, limitações e estrutura do trabalho}

O presente estudo tem por foco a análise dos critérios relevantes para a definição do conceito de beneficiário efetivo nos acordos internacionais contra a bitributação, nas suas diferentes correntes e variáveis, bem como abordar os problemas enfrentados na interpretação e aplicação desse conceito em razão do significado que ele carrega no âmbito internacional. Para tanto, nosso exame não será pautado em nenhum acordo contra a bitributação específico, mas sim na Convenção Modelo da OCDE, na sua versão de julho de 2008 (Convenção Modelo ou CM OCDE). Todas as referências à Convenção Modelo, no decorrer deste trabalho, referem-se a esta versão, salvo disposição específica em

\footnotetext{
${ }^{72}$ Cf. BAKER, Philip. Double taxation conventions and international tax law. 2nd ed. London: Sweet \& Maxwell, 1994. p. 6.

${ }^{73}$ A qualificação dos rendimentos nos acordos contra a bitributação é, também, extremamente importante para a sua aplicação, e representa tema de extrema complexidade. Cf SILVEIRA, Rodrigo Maitto da. Aplicação de tratados internacionais contra a bitributação: qualificação de partnership joint ventures, cit., p. 21-24.
} 
contrário. A Convenção Modelo da Organização das Nações Unidas (Convenção Modelo da ONU) e o Modelo de Tratados dos Estados Unidos da América (Modelo EUA) serão abordados quando cabíveis, em caráter especial.

Iniciaremos o nosso trabalho (Capítulo I) por meio da análise do conceito e tratamento jurídico do termo beneficiário efetivo e suas variáveis (tais como beneficial ownership, legal ownership e economic ownership, sempre que aplicáveis ao tema) no direito interno dos países que adotaram originalmente essa expressão, países estes pertencentes ao sistema de common law. Para tanto, uma análise dos diferentes atributos inerentes ao direito de propriedade desses países será realizada, bem como o entendimento jurisprudencial na interpretação e aplicação desse termo e suas variantes. Finalmente, a realidade do ordenamento jurídico brasileiro aplicável ao tema também não escapará do nosso estudo, tanto na parte relacionada ao direito de propriedade como àquela específica da legislação tributária que utiliza a referida expressão.

Posteriormente, analisaremos o tema da interpretação dos acordos internacionais contra a bitributação (Capítulo II). Por meio do processo interpretativo específico desses instrumentos pretendemos verificar suas etapas, formas, importância e consequências para a determinação do significado de beneficiário efetivo, bem como as implicações que decorrem desse processo exegético. Ainda neste capítulo trataremos dos diferentes instrumentos utilizados na interpretação dos tratados internacionais e, em especial, aqueles relacionados à construção de sentidos dos acordos contra a bitributação.

Ademais, no Capítulo III, examinaremos propriamente o conceito de beneficiário nos acordos internacionais contra a bitributação, abordando temas específicos importantes para a sua definição, tais como (i) requisitos para o usufruto dos benefícios dos acordos; (ii) sua origem, evolução e uso na CM OCDE e nos Comentários da $\mathrm{OCDE}^{74}$; (iii) formas e critérios pelos quais essa definição pode ser realizada; (iv) sua relação com o treaty shopping; e (v) a visão jurisprudencial no direito comparado e brasileiro sobre o tema.

Sempre que cabível e, desde que relevante para o tema, abordaremos a perspectiva do direito brasileiro sobre os assuntos analisados nos capítulos anteriores. Convém ressaltar que, em relação aos acordos brasileiros, não pretendemos apresentar uma análise crítica ou aprofundada de cada acordo específico, tampouco do tratamento do termo

\footnotetext{
${ }^{74}$ Os Comentários à Convenção Modelo da OCDE, instrumento que serve para esclarecer e expor as interpretações dos diferentes Estados Membros dessa organização mundial, serão referidos neste trabalho como Comentários da OCDE, Comentários à CM OCDE ou simplesmente Comentários.
} 
beneficiário efetivo no ordenamento jurídico brasileiro, mas sim examinar a conexão - quando cabível - com os temas aqui tratados. Ademais, apesar do tema se relacionar com a prática e limites dos acordos contra a bitributação na esfera do planejamento tributário internacional (seu uso e abuso), este tema não faz parte do escopo específico do presente estudo, sendo apenas analisado nos limites da sua relação com o conceito de beneficiário efetivo.

Ao final do trabalho apresentaremos uma síntese conclusiva deste estudo.

\section{Relevância, aplicação e justificativa do tema}

É inegável, há algum tempo, que os acordos internacionais contra a bitributação constituem uma importante forma de incentivar os investimentos internacionais e fomentar o crescimento econômico dos países signatários ${ }^{75}$. Apesar de reconhecemos que os acordos, por si só, não representam um mecanismo de fomento direto ao desenvolvimento dos Estados, não restam dúvidas de que o fenômeno da bitributação é prejudicial ao estímulo e aprimoramento do comércio internacional. Por este motivo, a celebração de acordos internacionais contra a bitributação gera certas garantias e benefícios, além de proporcionar maior segurança jurídica, aos investidores, contribuindo para a expansão das atividades econômicas transnacionais.

Ainda assim, os países em geral e, sobretudo, o Brasil ainda encontram dificuldades em razão do desconhecimento das normas de interpretação e aplicação dos acordos contra a bitributação, gerando considerável confusão nesta área. Desta forma, a escolha do tema ora apresentado tem por justificativa o interesse em aprofundar o conhecimento na área do direito tributário internacional. Com isso, pretende-se contribuir para uma maior e melhor compreensão das regras relacionadas à determinação do beneficiário efetivo dos rendimentos previstos nos acordos internacionais contra a bitributação e, em especial, sua adequada aplicação para as situações acima referidas.

O tema, portanto, apresenta uma grande importância no cenário jurídico-econômico mundial e, ao abranger matérias como a interpretação, aplicação e utilização indevida dos acordos contra a bitributação, se expande para a esfera do planejamento tributário internacional, em sentido amplo, atualmente um assunto de vital importância não só para os contribuintes como também para a administração pública dos países, em esfera global.

${ }^{75}$ Cf. ARNOLD, Brian J. et al. op. cit., p. 233. 


\section{CONCLUSÕES}

1. Em razão do princípio da relatividade dos tratados, os acordos internacionais contra a bitributação são formulados, em regra geral, para produzir efeitos apenas para pessoas residentes nos Estados Contratantes que dele são parte. Portanto, não devem conferir benefícios ou ter seus dispositivos estendidos para terceiros Estados que não participaram do processo de negociação e mútuas concessões que exige a celebração de um tratado tributário, salvo clara intenção das partes.

2. Em virtude da concorrência fiscal internacional gerada pelo fenômeno da globalização, os contribuintes que operam a nível transnacional buscam formas de estruturar seus negócios de forma a reduzir a carga fiscal incidente. Nesse sentido, muitas vezes fazem uso dos benefícios veiculados pelos acordos contra a bitributação com fim único ou precípuo de obter vantagens tributárias sem, contudo, cumprir com os requisitos mínimos para o treaty entitlement, prática essa conhecida como treaty shopping. Em razão de algumas falhas técnicas, limitações de direito interno ou objetivos secundários de um ou ambos os Estados Contratantes, os acordos baseados na CM OCDE permitem essa prática, sob diferentes níveis, a depender do texto do acordo e da legislação do país.

3. A partir do exame dos requisitos para uma pessoa fazer jus à aplicação dos Artigos 10 (Dividendos), 11 (Juros) e 12 (Royalties) da CM OCDE (treaty entitlement) pode-se constatar que eles consistem, geralmente, nos seguintes: (i) que ela seja considerada uma pessoa visada (Artigo $1^{\circ}$ da CM OCDE); (ii) que ela seja considerada residente em um dos Estados Contratantes (Artigo $4^{\circ}$ da CM OCDE); (iii) que os dividendos, juros e royalties sejam considerados pagos a essa pessoa; e (iv) que ela seja considerada como o beneficiário efetivo desses rendimentos.

4. Assim, o termo beneficiário efetivo incluído nos Artigos 10 (Dividendos), 11 (Juros) e 12 (Royalties) de um acordo internacional contra a bitributação é uma das condições necessárias para que as pessoas possam se beneficiar, isto é, fazer jus ao direito de usufruir alguns dos benefícios veiculados pelo acordo, especificamente para estes tipos de rendimentos. 
5. Caso o beneficiário efetivo não seja considerado um residente no outro Estado Contratante, o Estado da Fonte poderá tributar esses rendimentos de acordo com a sua lei interna, sem as limitações previstas no acordo contra a bitributação. Assim, o tema apresenta grande importância no cenário jurídico-econômico mundial, ao abranger matérias como a interpretação, aplicação e utilização indevida dos acordos contra a bitributação, i.e., treaty shopping.

6. Originalmente, o termo beneficiário efetivo decorreu da expressão inglesa beneficial owner, existente na lei doméstica dos países que adotam o sistema jurídico de common law, principalmente o Reino Unido (UK), onde esse termo surgiu pela primeira vez no contexto da trust law para diferenciar o conceito de legal ownership, para delimitar os atributos da propriedade do trustee e do beneficiário do trust. Pressupõe, assim, a análise da definição de propriedade e os direitos a ela inerentes, uma vez que é necessário definir quando e sob que circunstâncias um sujeito passa a deter a renda.

7. Ao examinar esse tratamento da propriedade no direito ingês, é necesário distinguir dois ramos distintos desse direito: a common law e equity. Enquanto a common law adota a posição de que a propriedade (ownership) é indivisível, o equity permite sua divisão entre legal title (propriedade legal) em uma pessoa e beneficial owner (ou equitable ownership) em outra. No caso de legal rights, a pessoa tem o título e o remédio legal, ao passo que os equitable rights ela somente possui o remédio legal, i.e., somente são exequiíveis em equity, sob a ação específica de cestui que trust.

8. Assim, na Inglaterra a distinção entre o direito de propriedade e o direito do beneficial owner é que o primeiro consiste em um direito real, oponível a todos. Já o direito do beneficial owner não pode ser considerado real, embora não seja somente um direito pessoal, oponível apenas entre as partes contratantes, mas também oponível a todos, exceto comprador de boa-fe que não tenha conhecimento da existência da propriedade de beneficial ownership. O direito canadense também adotado esse critério predominantemente jurídico na determinação do beneficial owner.

9. Nos EUA figura do beneficial owner também existe. Todavia, nesse país nota-se uma forte influência do princípio da prevalência da substância sobre a forma, baseado na aplicação de diversos testes de caráter econômico para verificação do direito de propriedade, uma vez que é possível a produção de resultados distintos 
daqueles no direito civil decorrentes do mesmo ato ou negócio jurídico em sua caracterização. O controle sobre a propriedade e a fruição dos benefícios econômicos (inclusive riscos de depreciação ou valorização do bem) são elementos fundamentais para a definição norte-americana de beneficial owner. Na Austrália, o termo beneficiário efetivo e suas derivações não possuem definição clara e específica até hoje.

10. Do ponto de vista geral, nos países de tradição de civil law há apenas um único proprietário, o titular legal da propriedade. Entretanto, existe a possibilidade de transferência do direito de uso do bem e de seus frutos a terceiros, mas segregação entre a propriedade legal e a econômica somente se dá no âmbito da liberdade de contratar dos particulares, e não em razão dos atributos jurídicos da propriedade, sendo assim, é uma limitação ao direito de propriedade e não um direito de propriedade autônomo.

11. No Brasil é possível afirmar que ser possível a segregação do direito de propriedade e seus atributos, em determinados casos, quando houver uma divisão entre os direitos do proprietário e os direitos econômicos de outro titular, tal como um usufrutuário, se previstos os requisitos em lei. Todavia, não há no direito privado brasileiro um conceito equivalente ou um instituto jurídico similar ao do beneficial owner existente na equity dos países de common law.

12. No que se refere especificamente direito tributário brasileiro, o termo beneficiário efetivo foi inicialmente utilizado no pela Lei $n^{\circ} 11.727 / 2008$, para ampliar a definição de país com tributação favorecida sujeitos às regras de preço de transferência. Entretanto, o tema ganhou maior notoriedade com a Lei $\mathrm{n}^{\circ}$ 12.249/2010, que definiu o termo como a pessoa (i) não tenha sido constituída com o único ou principal objetivo de economia tributária; e (ii) que aufira a renda por sua própria conta e não como um agente, administrador fiduciário ou mandatário por conta de terceiro.

13. Como regra geral, a interpretação dos acordos contra a bitributação deve ser feita com base nas regras do Direito Internacional Público, mais precisamente pelas regras presentes nos Artigos 31 a 33 da Convenção de Viena sobre o Direito dos Tratados, sendo permitido, excepcionalmente, a remissão ao direito interno dos Estados Contratantes somente nos casos previstos pelo Artigo 3(2) da Convenção 
Modelo da OCDE, isto é, quando o texto e contexto dos acordos não forem suficientes para a interpretação do significado de um termo do acordo.

14. A noção de contexto para fins do Artigo 3(2) da CM OCDE é extremamente ampla, permitindo sua construção por meio de diversos instrumentos consagrados na CVDT sendo, inclusive, mais amplo que o contexto mencionado na última, razão pela qual pode ser influenciada por outros instrumentos de soft law tais como os Comentários, Relatórios e Minutas de Discussão da OCDE, apesar de ser reconhecido que estes não são vinculantes à interpretação e aplicação dos acordos. Apesar de não vinculantes, os Comentários da OCDE, em especial, representam um valioso instrumento de interpretação para os acordos contra a bitributação que seguem a Convenção Modelo da OCDE, mesmo por Estados não-Membros, sendo consagrados internacionalmente por diversos países, inclusive em decisões judiciais, como ferramenta hermenêutica extremamente útil.

15. Em âmbito internacional, o termo (ou requisito) beneficiário efetivo foi originalmente introduzido na CM OCDE de 1977. De acordo com os Comentários, este termo foi incluído por duas razões essenciais: (i) para esclarecer o significado da expressão pagos a um residente (paid to a resident), utilizada nos artigos 10, 11 e 12 da CM, como regra relacionada a atribuição da renda; e (ii) para intensificar o combate ao treaty shopping, havendo discussão sobre qual foi a razão preponderante.

16. Nos acordos contra a bitributação celebrados por países que não adotam o idioma inglês como oficial, a tradução da expressão beneficiário efetivo pode levar a algumas diferenças de significado em razão dos termos utilizados, gerando confusão em sua interpretação e aplicação.

17. Os argumentos favoráveis a aplicação da definição de beneficiário efetivo decorrente de lei doméstica, em razão da remissão a lei interna, se baseiam na interpretação literal (plain language) do Artigo 3(2) da CM OCDE, que estabelece a remissão à lei interna quando a CM OCDE faz uso de um termo ou expressão que não possui definição expressa em seu texto, exceto se o contexto exija diferente.

18. Todavia, a maior parte da doutrina especializada entende que beneficiário efetivo deve ter um significado adstrito aos acordos contra a bitributação, i.e., deve ser um 
treaty concept e não um conceito definido por leis internas, não se admitindo a remissão ao direito interno prevista no Artigo 3(2) da CM OCDE.

19. Os Comentários aos Artigos 10, 11 e 12 da CM OCDE, deixam claro que agentes, mandatários e conduit companies agindo como fiduciárias ou administradores não são considerados como o beneficiário efetivo de dividendos, juros e royalties, haja vista que possuem apenas poderes restritos sobre a propriedade, agindo em nome de outrem (um terceiro) e não em nome próprio.

20. Entendemos que o termo beneficiário efetivo faz parte da linguagem fiscal internacional, refutando qualquer remissão ao direito interno por meio do Artigo 3(2) da CM OCDE para sua definição. Para nós, o beneficiário efetivo é a pessoa que detém a parte substancial dos atributos dos direitos de propriedade, quando comparada à outra pessoa que também possua algum desses atributos, a ponto de ser a titular jurídica da renda auferida em virtude da renda ter sido agregada ao seu patrimônio próprio, conferindo autonomia para essa pessoa decidir o que fazer com a renda percebida. Rejeitamos, assim, o critério econômico na interpretação do termo.

21. O debate sobre qual critério de interpretação deve prevalecer, se o econômico ou o jurídico, tem importantes implicações quanto escopo e limites do conceito de beneficiário efetivo nos acordos contra a bitributação, influenciando sobremaneira a questão de o combate o treaty shopping poder ser feito de forma geral (situações em geral) ou específica (situações específicas).

22. O fato de que existem medidas anti-abuso ad hoc específicas e separado nos acordos contra a bitributação somente confirma que tais medidas anti-abuso não podem ser consideradas implícitas em uma convenção somente por força da existência do termo beneficiário efetivo em seu texto. Portanto, entendemos que não se mostra correta a utilização do conceito de beneficiário efetivo no combate ao abuso no planejamento tributário internacional de forma ampla, configurando-se patente desvio do conceito originariamente desenvolvido e incluído na CM OCDE de 1977, servindo apenas para evitar o treaty shopping mais rudimentar e específico sobre o uso de intermediários atuando em nome de terceiros e apenas aplicável aos dividendos, juros e royalties. 
23. Alguns instrumentos editados pela OCDE, dentre os quais os relatórios de Harmful Tax Competition e o Double Taxation Conventions and the Use of Conduit Companies geraram confusão entre aplicação de medida de combates ao uso de estruturas abusivas e os propósitos do termo beneficiário efetivo, estendendo o combate a toda forma de treaty shopping, em caráter geral, para o uso daquele termo, o que foi uma verdadeira impropriedade, em razão da clara especificidade e aplicação restrita desse termo, em comparação a outras medidas genéricas de prevenção de abuso nos acordos.

24. Assim, partilhamos da opinião de que o conceito de beneficiário efetivo é um meio de eficácia limitada na prevenção da evasão fiscal internacional. É exatamente nesse contexto que ganham importância as cláusulas de limitação de benefícios ou cláusulas LOB, parte do Artigo 22 do Modelo EUA, também mencionadas nos Comentários da CM OCDE ao Artigo $1^{\circ}$. Este artigo teve por objetivo incluir, nos acordos internacionais contra a bitributação, condições mínimas para que apenas as pessoas que tivessem um propósito negocial real pudessem fazer jus aos benefícios de um acordo. Essas condições são exigidas e verificadas por de testes objetivos, reduzindo o subjetivismo na apreciação de eventual existência de abuso dos acordos.

25. Apesar de a OCDE não ter estabelecido técnicas específicas e permanentes de combate e prevenção ao abuso ou uso impróprio dos acordos contra a bitributação, incluiu, nos Comentários ao Artigo $1^{\circ}$ da CM OCDE de 2003, uma série de modelos de cláusulas de limitação de benefícios recomendáveis aos países que desejam prevenir o treaty shopping e o treaty abuse, notadamente o (i) lookthrough approach; (ii) subject-to-tax approach; (iii) channel approach; (iv) exclusion approach; e (v) cláusulas de salvaguarda (bona fide).

26. O Brasil não adota, na maioria de seus acordos vigentes, cláusulas de LOB e, nos poucos em que adota estas cláusulas são mais básicas, simples e dotadas de certa subjetividade quando comparadas àquelas do modelo norte-americano e as sugeridas pelos Comentários da OCDE. Os acordos brasileiros mais recentes contêm alguns dispositivos nesse sentido, tais como aqueles celebrados com Chile, Israel, México, África do Sul e Peru. 
27. Por força da existência e dos objetivos que norteiam as cláusulas LOB, entendemos que não existe um princípio implícito anti-abuso nos acordos contra a bitributação, devendo qualquer restrição ao usufruto de seus benefícios ser feita por meio de disposições expressas no seu texto. Desta forma, em caso de inexistência do termo beneficiário efetivo nos acordos contra a bitributação, sua interpretação não deve pressupô-lo.

28. Em sentido semelhante, somos da opinião de que conceito de beneficiário efetivo não deve ser estendido aos demais artigos dos acordos, tais como ganhos de capital e outros rendimentos, em sentido contrário à posição recentemente adotada na Índia por meio do Caso Idea Cellular.

29. A atual jurisprudência sobre o tema, no direito comparado, demonstra a ausência de consenso sobre o conceito de beneficiário efetivo, seu critério de interpretação e seus limites no combate ao treaty shopping e ao abuso dos acordos, tendo como notório precedente - ainda que indireto - o caso Aiken Industries nos EUA da década de 70, apesar da ausência deste termo no acordo que envolvia esse julgado. $\mathrm{Na}$ França e no Reino Unido, dois precedentes contrários ao contribuinte basearamse no critério econômico, porém adotaram entendimentos diferentes sobre o significado de beneficiário efetivo: o primeiro consagrou a aplicação de normas internas em sua definição, ao passo que o segundo se posicionou favorável a uma definição decorrente de uma linguagem fiscal internacional. A China, em sua legislação interna, também prima pelo critério econômico do substance over form na definição do termo.

30. No Canadá, a decisão mais recente (Caso Prévost) privilegiou o critério jurídico e a aplicação da linguagem fiscal internacional, entendendo que, na medida em que uma sociedade holding detinha a titularidade jurídica da participação na sociedade canadense, bem como o poder de deliberar sobre o uso e eventual distribuição de dividendos, a holding seria o beneficiário efetivo dos dividendos para fins de aplicação do acordo contra a bitributação. Neste precedente, o significado fiscal internacional foi, inclusive, confirmado por meio da utilização dos Comentários da OCDE na definição desse termo. 
31. Especificamente no que diz respeito ao conceito de beneficiário efetivo no Brasil, a maior parte dos acordos (21 dos 29 em plena vigência) possui esse termo em seu texto, apesar de alguns acordos, como o celebrado com o Japão, não possuírem tal menção. A jurisprudência sobre o tema no país ainda é demasiadamente escassa, restringindo-se a dois casos: um administrativo (Caso TIM Nordeste) e outro judicial (Caso Volvo), que não abordam especificamente a definição do termo em suas decisões. No primeiro caso entendeu-se que um agente pagador residente no Japão era o beneficiário efetivo dos juros, em razão da inexistência desse requisito no Acordo Brasil-Japão, apesar de a decisão ter versado sobre pagamentos de comissão de corretagem, e não propriamente juros. No segundo caso, o STJ entendeu não ser possível a aplicação do Acordo Brasil-Japão em razão da ausência de bitributação no caso em questão, já que os juros recebidos por uma filial do banco japonês eram isentos no Panamá (por lei interna), sequer fazendo referência direta ao conceito de beneficiário efetivo.

32. Para nós, acertou o Conselho Administrativo de Recursos Fiscais ao analisar, no Caso TIM Nordeste, os requisitos do treaty entitlement presentes no Acordo BrasilJapão e ao interpretar que o treaty shopping - precisamente por ausência do termo beneficiário efetivo e das cláusulas LOB - não é vedado, em certa sintonia com o que se decidiu no Caso Azadi Bachao Andolan, na Índia. Por outro lado, equivocou-se o STJ, tanto por basear seu argumento na ausência de bitributação efetiva no caso, como por desconsiderar o treaty entitlement da filial panamenha que não consiste em pessoa jurídica distinta da do banco residente no Japão, mas sim uma extensão da própria personalidade jurídica da sociedade matriz sediada no Japão. Ademais, a ausência de cláusula LOB reitera que o direito daquela filial aos benefícios do mencionado tratado.

33. Cabe ressaltar, ainda, que a recente Minuta de Discussão da OCDE sobre o conceito de beneficiário efetivo apenas confirma o entendimento que defendemos, com suporte em parte da doutrina, de que o beneficiário efetivo é essencialmente uma regra de atribuição de renda e, portanto, seu uso é restrito ao combate ao treaty shopping específico e não do abuso dos acordos contra a bitributação que fogem aos casos envolvendo intermediários agindo em nome de terceiros, especificamente relacionados a dividendos, juros e royalties. Ratifica, também, que o critério de interpretação do direito de propriedade da renda deve ser preponderantemente o 
jurídico, e que a inclusão desse termo na CM OCDE jamais teve intenção de fazer referência à lei interna quando utilizou tal termo (rejeitando, assim, a aplicação automática do significado decorrente dos países de common law).

34. Entendemos, portanto, que o beneficiário efetivo dos acordos é: um conceito jurídico (e não econômico) de atribuição de renda (e não de abuso de acordos contra a bitributação), definido por linguagem fiscal internacional (e não por remissão à lei interna dos Estados Contratantes), cuja aplicabilidade é restrita ao combate do treaty shopping específico (e não geral) envolvendo exclusivamente rendimentos decorrentes de dividendos, juros e royalties (e não todos os tipos de renda), podendo ser utilizado apenas em casos de referência expressa no texto do acordo (e não implicitamente por força de princípio geral internacional).

35. Por fim, é imperioso ressaltar que, sem qualquer prejuízo das opiniões e conclusões anteriormente expostas, o acordo internacional contra a bitributação é um instrumento específico negociado entre dois Estados soberanos e, portanto, cada acordo é único, requerendo interpretação individual para cada caso. Assim, não obstante o termo beneficiário efetivo possuir sua definição no direito tributário internacional, por meio de um significado fiscal internacional na comunidade jurídica, é possível que determinado acordo o defina de forma distinta, ampliando, restringindo ou até excluindo (como é o caso do acordo Brasil-Japão, por exemplo) esse conceito da interpretação e aplicação daquele acordo. Em razão do pacta sunt servanda, as partes estão livres para definir as obrigações a que se vinculam por consenso, não obstante a prática tributária internacional demonstrar que não é usual a definição expressa do termo beneficiário efetivo nos acordos contra a bitributação, razão pela qual adotamos a definição acima descrita. 


\section{REFERÊNCIAS BIBLIOGRÁFICAS}

ACCIOLY, Hildebrando; SILVA, Geraldo Eulálio do Nascimento e. Manual de direito internacional público. 14 ed. São Paulo: Saraiva, 2000.

ALCKMIN, Alexandre. Dupla Não-tributação: entre o poder de tributar e as convenções internacionais em matéria fiscal. In: TÔRRES, Heleno Taveira (Coord.). Direito internacional tributário aplicado. São Paulo: Quartier Latin, 2004. v. 4.

ANDRADE, Manuel A. Domingues de. Ensaio sobre a teoria da interpretação das leis. 4. ed. Coimbra: Armênio Amado, 1987. (Coleção Stvdivm - Temas filosóficos, jurídicos e sociais).

ANDRADE FILHO, Edmar Oliveira. Interpretação e aplicação de normas de direito tributário. São Paulo: Ed. CID, 2002.

ARGINELLI, Paolo. The Royal Bank of Scotland case: more controversy on the interpretation of the term 'beneficial owner'. In: RUSSO, Raffaele; FONTANA, Renata (Coords.). A decade of case law: essays in honour of the 10th anniversary of the Leiden Adv LLM in international tax law. Leiden: ITC/IBFD, 2008.

ARNOLD, Brian J. Tax treaties and tax avoidance: the 2003 revisions to the commentary to the OECD Model. Bulletin for International Taxation, Amsterdam, June 2004.

Tax treaty monitor. Bulletin for International Taxation, v. 63, n. 5/6, 2009.

.. et al. Summary of the Proceedings of an Invitational Seminar on Tax Treaties in the 21st Century. Bulletin - Tax Treaty Monitor, Amsterdam, June 2002.

AULT, Hugh J. The role of the OECD commentaries in the interpretation of tax treaties, Intertax, n. 4, 1994.

In: VOGEL, Klaus (Chair). The OECD Model Convention - 1998 and Beyond; The Concept of Beneficial Ownership in Tax Treaties - Proceedings of a Seminar held in London, in 1998 during the $52^{\text {nd }}$ Congress of the International Fiscal Association. The Hague: Kluwer Law International, 2000. v. 23a.

AUSTRALIAN GOVERNMENT. Disponível em: $<$ http://law.ato.gov.au/atolaw/view.htm?locid='JUD/*1976*1AC167'\&PiT=999912312359 58>. Acesso em: 04 jan. 2012. 
AUSTRALIAN GOVERNMENT. Disponível em: <http://law.ato.gov.au>.

AUSTRY, Stéphane; GELIN, Stéphane; SOREL, David. Practical effectiveness of beneficial ownership clauses in France's tax treaties. Tax Notes International, v. 53, n. 2, 2009.

AVI-YONAH; Reuven; PANAYI, Christiana HJI. Rethinking treaty shopping: lessons for the European Union 2, Public Law and Legal Theory Working Paper Series, Working Paper, n. 182, p. 2, Jan. 2010.

BAKER, P. V.; LANGAN, P. St. Snell's principles of equity. 28th ed. London: Sweet \& Maxwell, 1982.

BAKER, Philip. Beneficial ownership: after indofood. Grays Inn Tax Chamber Review, v. 6, n. 1, p. 15-28.

. Double tax conventions. London: Sweet \& Maxwell, 2002.

Double taxation conventions and international tax law. 2nd ed. London: Sweet \& Maxwell, 1994.

. Report Possible Extension of Beneficial Ownership Concept, presented at the Fourth Session of the UN Economic and Social Council, Committee of Experts on International Cooperation in Tax Matters, Geneva, 20-24 October 2008. Disponível em: <http://www.un.org/esa/ffd/tax/fourthsession/index.htm>, p. 4. Acesso em: 11 dez. 2011.

. A tributação internacional no século XXI. Direito Tributário Atual, São Paulo, n. 19, p. 41, 2005.

BAMMENS, Niels; DE BROE, Luc. Treaty shopping and avoidance of abuse. In: LANG, Michael et al. (Ed.). Tax treaties: building bridges between law and economics. Amsterdam: IBFD, 2010.

BARRETO, Paulo Ayres. Elisão tributária: limites normativos. Tese (Livre-docência) Faculdade de Direito da Universidade de São Paulo, São Paulo, 2008.

. Imposto sobre a renda e preços de transferência. São Paulo: Dialética, 2001.

BELL, Andrew P. Modern law of personal property in England and Ireland. London: Butterworths, 1989.

BELLAN, Daniel Vitor. Interpretação dos tratados internacionais em matéria tributária. In: TORRES, Heleno Taveira (Coord.). Direito tributário internacional aplicado. São Paulo: Quartier Latin, 2005. v. 3. 
BERG, A.G.J. Options and beneficial owner. The Law Quarterly Review, n. 1, 1992.

BERNSTEIN, Jack; SUMMERHILL, Louise. Canada's Prévost Decision: the world is watching. Tax Notes International, v. 53, n. 11, 2009.

BIANCO, João Francisco. Planejamento tributário: estudo de casos e exame crítico da jurisprudência. In: YAMASHITA, Douglas (Coord). Planejamento tributário à luz da jurisprudência. São Paulo: Lex, 2007.

; NEWTON, Raquel. Beneficiário efetivo. Revista Direito Tributário Atual, São Paulo, n. 26, 2011.

BITTKER, Boris I.; LOKKEN, Lawrence. Fundamentals of international taxation - U.S. taxation of foreign income and foreign taxpayers. Warren: Gorham \& Lamont RIA, 2001.

BIZIOLI, Gianluigi. Tax treaty interpretation in Italy. In: LANG, Michael (Coord.). Tax treaty interpretation. The Hague. Kluwer Law International, 2000.

BOGERT, George T. Trusts. Minnesota: West Publishing, 1987.

BOIDMAN, Nathan; KANDEV, Michael. Canadian Taxpayer Wins Prévost Appeal. Tax Notes International, v. 53, n. 10, 2009.

BORGES, Antônio de Moura. Convenções sobre dupla tributação internacional. Teresina: EDIFPI; São Paulo: IBDT, 1992.

BORGES, Ricardo Henrique da Palma; RESENDE, Raquel Maria Maymone. Tax treaty interpretation in Portugal. In: LANG, Michael (Coord.). Tax treaty interpretation. The Hague: Kluwer Law International, 2000.

BROWNLIE, Ian. Princípios de direito internacional privado. Trad. Maria Manuela Farrajota et al. Lisboa: Fundação Calouste Gulbenkian, 1997.

CALIENDO, Paulo. Estabelecimentos permanentes em direito tributário internacional. São Paulo: Ed. Revista dos Tribunais, 2005.

CAMPOS, Diogo Leite de. Sistema tributário no Estado dos Cidadãos. Coimbra, Almedina, 2006.

CASSESE, Antonio. International law. 2nd. ed. Oxford: Oxford University Press. 2005.

CASTRO, Leonardo Freitas de Moraes e. Análise da aplicação da teoria do substance over form aos planejamentos tributários no Brasil. Revista de Direito Tributário da APET, São Paulo, n. 22, 2009. 
CASTRO, Leonardo Freitas de Moraes e. Considerações sobre o tratamento das entidades híbridas e dos instrumentos financeiros híbridos na convenção Modelo da OCDE. Revista de Direito Tributário Internacional, São Paulo, v. 12, p. 135-156, 2009.

Inadimplemento da obrigação tributária na composição do preço predatório e sua relação com a livre concorrência. Direito Tributário Atual, São Paulo, n. 22, p. 235-256, 2008.

Parallel treaties e a interpretação dos acordos para evitar a dupla tributação: a experiência brasileira em face dos artigos 7, 12 e 21 da Convenção Modelo OCDE. In: MONTEIRO, Alexandre Luiz Moraes do Rego; CASTRO, Leonardo Freitas de Moraes e; UCHÔA FILHO, Sérgio Papini de Mendonça (Coords.). Tributação, comércio e solução de controvérsias internacionais. São Paulo: Quartier Latin, 2011.

; SANTOS, Celso Araújo. Caso TIM Nordeste: aplicação do Tratado Brasil-Japão na remessa de juros decorrentes de eurobonds. In: CASTRO, Leonardo Freitas de Moraes e. et al. (Orgs.). Tributação Internacional: análise de casos, Sao Paulo: MP Ed., 2010.

.; SILVEIRA, Rodrigo Maitto da; GRISI FILHO, Celso Cláudio de Hildebrand e. Caso Volvo 1: Possibilidade de Aplicacao do Art. 10 (Juros) do Tratado Brasil-Japao a Filial de Banco Japones Sediada no Panama. In: CASTRO, Leonardo Freitas de Moraes e. et al. (Orgs.). Tributação Internacional: análise de casos, Sao Paulo: MP Ed., 2010.

; UCHÔA FILHO, Sérgio Papini de Mendonca. Reflexões sobre os princípios constitucionais aplicáveis as regras de subcapitalização brasileiras veiculadas pela Med.Prov. 472/2009 e eficácia de sua conversão na lei 12.249/2010 para fins de IRPJ e CSLL. Revista Tributária e de Finanças Públicas, São Paulo, v. 96, p. 221-240, 2011.

CATÃO, Marcos André Vinhas. A "cláusula de beneficiário efetivo": limite de sua aplicação. In: TÔRRES, Heleno Taveira (Coord.). Direito internacional tributario aplicado. São Paulo, Quartier Latin, 2004. v. 2.

CONVENÇÃO DE VIENA SOBRE O DIREITO DOS TRATADOS. Disponível em: <http://www2.mre.gov.br/dai/dtrat.htm>. Acesso em: 11 dez. 2011.

COUZIN, Robert. Corporate residence and international taxation. Amsterdam: IBFD, 2002.

CUNNINGHAM, Noel B.; SCHENK, Deborah H. Taxation without realization: a revolutionary approach to ownership. Tax Law Review, n. 4, 1992.

DANON, Robert J. Le concept de bénéficiaire effective dans le cadre du MC OCDE. In: IFF Forum für Steuerrecht 1, 2007. 
DANON, Robert J. Switzerland's direct and international taxation of private express trusts. Zurich: Schulthess, 2004.

DAVID, René; BRIERLEY, John E.C. Major legal systems in the world today. 3rd ed. London: Stevens \& Sons, 1985.

DE BROE, Luc. International tax planning and prevention of abuse. Amsterdam: IBFD, 2008. (Doctoral Series, 14).

DEPARTMENT OF TREASURY, US Model Income Tax Convention, Nov. 15, 2006. Disponível em: $<$ http://www.irs.gov/businesses/international/article/0,,id=169597,00.html>. Acesso em: 20 dez. 2011.

DIAS, R. M. W. Jurisprudence. 5th ed. London: Butterworths, 1985.

DINH, Nguyen Quoc.; DAILLER, Patrick; PELLET, Alain. Direito internacional público. Trad. Vítor Marques Coelho. 2 ed. Lisboa: Fundação Calouste Gulbenkian, 2003.

DOLINGER, Jacob. Direito internacional privado. 6. ed. Rio de Janeiro: Renovar, 2001. . As soluções da suprema corte brasileira para os conflitos entre o direito interno e o direito internacional: um exercício de ecletismo. Revista Forense, Rio de Janeiro, v. 334, abr./jun. 1996.

DORNELLES, Francisco Oswaldo Neves. Acordos para eliminar a dupla tributação da renda. Revista de Direito Tributário, São Paulo, n. 83, p. 251-257, jan./mar. 1978.

DUFF, David G. Responses to treaty shopping: a comparative evaluation. In: LANG, Michael et al. (Ed.). Tax treaties: building bridges between law and economics. Amsterdam, IBFD, 2010,

ELLIS, Maarten J. The influence of the OECD commentaries on treaty interpretation response to Prof. Dr. Klaus Vogel. Bulletin - Tax Treaty Monitor, Dec. 2000.

ENGELEN, Frank. Interpretation of tax treaties under international law. Amsterdam: IBFD, 2004.

; POTGENS, Frank P. Report on the application of the OECD model tax convention to partnerships' and the interpretation of tax treaties. Bulletin - European Taxation, Amsterdam: IBFD, p. 265-266, July 2000.

FABER, Peter L. et al. The ownership and disposition of property: new rules for old problems, taxes. The Tax Magazine, n. 12, 1997. 
FEDERAL COURT OF APPEAL. Disponível em: <http://www.fca-caf.gc.ca>. Acesso em: 08 mar. 2011.

FERNANDEZ DE CASADEVANTE ROMANÍ, Carlos. Interpretación de las normas internacionales. Panplona: Aranzadi, 1996.

FERRARA, Francesco. Interpretação e aplicação das leis. Trad. Manuel A. Domingues de Andrade. 4. ed. Coimbra: Armênio Amado Editor, 1987.

FERRAZ JR., Tércio Sampaio. Introdução ao estudo do direito: técnica, decisão, dominação. 2. ed. São Paulo: Atlas, 1996.

FINANCE Act $1967 . \quad$ Disponível em: <http://www.legislation.gov.uk/ukpga/1967/54/section/27>. Acesso em: 07 jan. 2012.

FRASER, Ross; OLIVER, J.D.B. Beneficial ownership: HMRC's draft guidance on interpretation of the indofood decision. British Tax Review, n. 1, 2007.

; _. Treaty shopping and beneficial ownership: Indofood International Finance Limited v. JP Morgan Chase Bank, N.A., London Branch. British Tax Review, n. 4, p. 422-426, 2006.

GARBARINO, Carlo. La tassazione del reddito transnazionale. Padova: CEDAM, 1990.

GARCIA NOVOA, César. Interpretación de los convenios de doble inposición internacional. In: GODOY, Juan Pablo F. Estudios de derecho internacional tributario: los Convenios de Doble Inposición. Bogotá: LEGIS, 2006.

GIBERT, Bruno; OUAMRANE, Yacine. Beneficial ownership: a french perspective. European Taxation, v. 48, n. 1, 2008.

GIULIANI, Federico Maria. La interpretazione delle Convenzioni Internazionali contro le doppie imposizioni sui redditi. In: UCKMAR, Victor (Coord.). Corso di diritto tributário internazionale. 2. ed. Padova: CEDAM, 2002.

GODOI, Marciano Seabra de. Os tratados ou convenções internacionais para evitar a dupla tributação e sua hierarquia normativa no direito brasileiro: In: SCHOUERI, Luis Eduardo (Coord.). Direito Tributário (Homenagem a Alcides Jorge Costa). São Paulo: Quartier Latin, 2003.v. 2.

GOODE, Roy. Commercial law. 2nd ed. London, Penguin Books, 1996.

GOUTHIÈRE. In: VOGEL, Klaus (Chair). The OECD Model Convention - 1998 and Beyond; The Concept of Beneficial Ownership in Tax Treaties - Proceedings of a Seminar held in London, in 1998 during the $52^{\text {nd }}$ Congress of the International Fiscal Association. The Hague: Kluwer Law International, 2000. v. 23a. 
GOUVEIA, Jorge Bacelar. Manual de direito internacional público. Rio de Janeiro: Renovar, 2005.

GRAU, Eros Roberto. O direito posto e o direito pressuposto. 1. ed. São Paulo: Malheiros Editores, 1996.

GRECO, Marco Aurélio. Planejamento fiscal e interpretação da lei tributária. São Paulo: Dialética, 1998.

GUSTAFSON, Charles; PERONI, Robert; PUGH, Richard. Taxation of international transactions: materials, texts and problems. 3rd ed. Thompson, 2007 (American Casebook Series, West).

HARTZ, Wilhelm. Interpretação da lei tributária: conteúdo e limites do critério econômico. Trad. Brandão Machado. São Paulo: Resenha Tributária, 1993.

HAY, Peter. An introduction to U.S. law. 2nd ed. Salem: Butterworth Legal Publishers, 1991.

HELMUT, Becker; WURM, Felix J. Survey. In: Treaty Shopping: an emerging tax issue and its present status in various countries $1,1988$.

HONORÉ, Anthony M. Ownership. In: GUEST, A.G. Oxford Essays in Jurisprudence. Oxford: Oxford University Press. 1961.

HOORN JR., J. van. Bitributação: uma tentativa de definição. In: MACHADO, Brandão (Coord.). Direito tributário (estudos em homenagem ao Prof. Ruy Barbosa Nogueira). São Paulo, Saraiva, 1994.

HUCK, Hermes Marcelo. Evasão e elisão: rotas nacionais e internacionais do planejamento tributário. São Paulo: Saraiva, 1997.

IBFD. International Tax Glossary. Ed. Susan M. Lyons. 2. ed. Amsterdam, 1992.

INTM332050 - Double taxation applications and claims: HMRC's reaction to Indofood case. Disponível em: <www.hmrc.gov.uk/manuals/intmanual/INTM332050.htm>. Acesso em: 18 nov. 2011.

JONES, John F. Avery. British Report. In: IFA. Cahiers de Droit Fiscal Internacional: Interpretation of Double Taxation Conventions. Deventer, 1993. v. 78.

Conflicts of qualification: comment on Prof. Vogel's and Alexander Rust's articles. Bulletin of International Bureau of Fiscal Documentation - Tax Treaty Monitor, p. 184-186, May 2003. 
JONES, John F. Avery. Credit and exemption under tax treaties in case of differing income charactereization. Diritto e Pratica Tributaria, v. 77, n. 3, p. 754, 1996.

. The effect of changes in the OECD commentaries after a treaty is concluded. Bulletin for International Bureau of Fiscal Documentation, Amsterdam, March 2002.

JONES, John F. Avery. Problems of categorizing tncome for tax treaty purposes. In: KIRCHHOF, Paul; LEHNER, Moris; Raad, KEES van et al. (Coord.). International and comparative taxation: essays in honour of Klaus Vogel. The Hague: Kluwer Law International, 2002.

. Tax treaty interpretation in the United Kingdom. In: LANG, Michael (Coord.). Tax treaty interpretation. The Hague: Kluwer Law International, 2000.

. The treatment of trusts under the OECD Model Convention. European Taxation, Amsterdam, n. 12, 1989.

et al. The interpretation of tax treaties with particular reference to article 3(2) of he OECD model. British: Tax Review, 1984.

et al. The origins of concepts and expressions Used in the OECD Model and their Adoption by States. Bulletin - Tax Treaty Monitor, Amsterdam, June 2006.

et al. Tax treaty problems relating to source. European Taxation, Amsterdam, IBFD, p. 78-93.

; ELLIS, Maarten J.; MAISTO, Guglielmo et al. The interpretation of income tax treaties with particular reference to the commentaries on the OECD model. Amsterdam: IBFD, 2006.

KANDEV, Michael. Treaty Shopping in Canada: the Door is (Still) Open. Bulletin for International Taxation, v. 62, n. 10, 2008.

KEENAN, Dennis. Smith and Keenan's english law. London: Pitman, 10th ed., 1992.

Disponível em:

<http://law.ato.gov.au/atolaw/view.htm?docid=TXD/TD200825/NAT/ATO/00001>. Acesso em: 03 jan. 2012.

KIENBERGER, S. Avoidance of double (non-)taxation and art. 23 A and B paragraph 1 OECD MC. In: Conflicts of qualification in tax treaty law. Wien: Linde, 2007.

KOTZ, K.; ZWEIGERT; H. An introduction to comparative law. 2nd ed. Oxford: Claredon Press, 1992. 
LANG, Michael. CFC Regulations and double tax treaties. Bulletin for International Fiscal Documentation, Amsterdam, 2003.

. Taxation of income in the hands of different taxpayers from the viewpoint of tax treaty law. Bulletin - Tax Treaty Monitor, Dec. 2001.

LINARES LUQUE, Alejandro M. El concepto de beneficiario efectivo en los convenios para evitar la doble imposición, como prevención de la elusión fiscal internacional. In: COLÓQUIO INTERNACIONAL DE DIREITO TRIBUTÁRIO, 5. Buenos Aires: La Ley, 2003.

LINN, Alexander. Branch report: Germany. IFA: Tax treaties and tax avoidance: application on anti-avoidance provisions, cahiers de droit fiscal international, The Hague, v. 95, p. 333-354, 2010.

LUKOFF, Frederick L. dividend, interest, royalties: the 'beneficial ownership' change in the 1974 amendments to the OECD Draft Convention. Taxes - The Tax Magazine, n. 8, 1977.

LÜTHI. In: VOGEL, Klaus (Chair). The OECD Model Convention - 1998 and Beyond; The Concept of Beneficial Ownership in Tax Treaties - Proceedings of a Seminar held in London, in 1998 during the $52^{\text {nd }}$ Congress of the International Fiscal Association. The Hague: Kluwer Law International, 2000. v. 23a.

MARTÍN JIMÉNEZ, Adolfo. Beneficial ownership: current trends. World Tax Journal, Amsterdam, n. 2. 2010.

Domestic anti-abuse rules and double taxation treaties (Part I). Bulletin of International Fiscal Documentation, v. 56, n. 11, p. 542-553, 2002.

- Domestic anti-abuse rules and double taxation treaties (Part II). Bulletin of International Fiscal Documentation, v. 56, n. 12, 2002.

. The 2003 revision of the OECD commentaries on improper use of tax treaties: a case of declining effect of the OECD Commentaries? Bulletin for International Taxation, Amsterdam, p. 27-28, Jan. 2004.

MAZZUOLI, Valério de Oliveira. Curso de direito internacional público. São Paulo: Ed. Revista dos Tribunais, 2006.

McDANIEL, Paul R.; McMAHON JR., Martin J.; SIMMONS, Daniel L.; POLSKY, Gregg. Federal income taxation cases and materials. 3rd ed. New York: Foundation Press, 1994. 
MEDEIROS, Antônio Paulo Cachapuz de. O poder de celebrar tratados: competência dos poderes constituídos para a celebração de tratados, à luz do direito internacional, do direito comparado e do direito constitucional brasileiro. Porto Alegre: Sérgio Antonio Fabris, 1995.

MEGARRY, Robert; WADE, H.W.R. The law of real property. 4th ed. London: Steven \& Sons, 1975.

MEHREN, Arthur Taylor von. Law in the United States: a general and comparative view. 1988.

MONTEIRO, Washington de Barros. Curso de direito civil: direito das coisas. 38 ed. São Paulo: Saraiva, 2007.

MOOIJ. In: VOGEL, Klaus (Chair). The OECD Model Convention - 1998 and Beyond; The Concept of Beneficial Ownership in Tax Treaties - Proceedings of a Seminar held in London, in 1998 during the $52^{\text {nd }}$ Congress of the International Fiscal Association. The Hague: Kluwer Law International, 2000. v. 23a.

NASSER, Salem Hikmat. Direito internacional do meio ambiente, direito transformado, jus cogens e soft law. In: NASSER, Salem Hikmat; REIS, Fernando Baldy dos (Orgs.), Direito internacional do meio ambiente: estudos em homenagem ao Prof. Guido Fernando Silva Soares. São Paulo: Atlas, 2006.

NEVES, Antonio Castanheira. O actual problema metodológico da interpretação jurídica. Coimbra: Coimbra Ed., 2003. v. 1.

Digesta: escritos acerca do direito, do pensamento jurídico, da sua metodologia e outros. Coimbra: Coimbra Ed., 1995. v. 2.

NOGUEIRA, Ruy Barbosa. Curso de direito tributário. 13 ed. São Paulo: Saraiva, 1994.

Da interpretação e da aplicação das leis tributárias. 2. ed. São Paulo: José Bushatsky Editor, 1974.

OECD, Clarification of the Meaning of "Beneficial Owner" in the OECD Model Tax Convention Discussion Draft (OECD 2011). International Organizations' Documentation IBFD, at Para. 12.1, p. 3. Disponível em: <www.oecd.org/dataoecd/49/35/47643872.pdf>. Acesso em: 17 nov. 2011.

. Double Taxation Conventions and the use of conduit companies. In: ORGANISATION FOR ECONOMIC CO-OPERATION AND DEVELOPMENT. International Tax Avoidance and Evasion: four related studies. Paris: OECD, 1987. (Issues of International Taxation, n. 1).

Harmful Tax Competition - an emerging global issue. Paris: OECD, 1998. 
OCDE. Issues in international taxation $n^{\circ}$ 6: the application of the OECD model tax convention to partnerships. Paris: OECD, 1999.

Modelo de Convenção Fiscal sobre o Rendimento e o Património. Versão condensada. Comité dos Assuntos fiscais da OCDE. Cadernos de Ciência e Técnica Fiscal, Coimbra, n. 197, 2005.

OECD Report. The Application of the OECD MC to Partnerships. Paris: OECD, 1999.

OLIVER, J. David B.; LIBIN, Jerome B.; WEEGHEL, Stef van; TOIT, Charl P. du. Beneficial ownership. Bulletin - International Bureau of Fiscal Documentation, Amsterdam, n. 7, p. 319-320, July 2000.

PALLESI, Niccolo. The application of tax treaties to investment funds. Berkley: University of California 2007. Disponível em: <Berkley Electronic Press (bepress)>. Acesso em: 12 jul. 2008.

PASIN, João Bosco Coelho. O conceito de beneficiário efetivo nos convênios para evitar dupla imposição, como prevenção da elisão fiscal internacional. In: COLÓQUIO INTERNACIONAL DE DIREITO TRIBUTÁRIO, 5. Buenos Aires: La Ley, 2003.

PEDRAZA, Luz Maria. Branch report: Peru. IFA: Tax treaties and tax avoidance: application on anti-avoidance provisions, cahiers de droit fiscal international, The Hague, v. 95a, 2010.

PETERS, Faustina G. F.; ROELOFSEN, Aart. Branch Report: Netherlands. IFA: Tax treaties and tax avoidance: application on anti-avoidance provisions, cahiers de droit fiscal international, The Hague, v. 95a, 2010.

PHILLIPS, Jeremy; FIRTH Alison. Introduction to intellectual property law. 2nd ed. London: Butterworths, 1990.

PIJL, Hans. The definition of 'beneficial owner' under dutch law, Bulletin for International Fiscal Documentation, v. 54, n. 6, p. 256-260, 2000.

Os comentários da OCDE como fonte do direito internacional e o papel do Poder Judiciário. Trad. Luiz Carlos de Andrade Jr. Revista de Direito Tributário Internacional, São Paulo, n. 4, p. 207-208, 2006.

PIRES, Manuel. International juridical double taxation of income. Deventer: Kluwer Academic Publishers, 1989.

PROKISCH, Rainer. Does it make sense if we speak of an "international tax language"? In: VOGEL, Klau (Coord.). Interpretation of tax law and treaties and transfer pricing in Japan and Germany. The Hague: Kluwer Law International, 1998. 
PROKISCH, Rainer. A intepretação dos tratados de dupla tributação. Fisco, n. 68, 1994.

QUEIROZ, Cristina. Interpretação constitucional e poder judicial: sobre a epistemologia da construção constitucional. Coimbra: Coimbra Ed., 2000.

RAAD, Kees van. Advanced course in international tax law. São Paulo: IBDT; ITC, 24-26 nov. 2008. Apostila.

Dual residence and 1977 OECD model treaty article 4(1), second sentence, ineuropean taxation. Amsterdam: IBFD, Jan. 1999.

. International coordination of tax treaty interpretation and application, In: In: KIRCHHOF, Paul; LEHNER, Moris; Raad, KEES van et al. (Coord.). International and comparative taxation: essays in honour of Klaus Vogel. The Hague: Kluwer Law International, 2002.

. Materials on international \& EC tax law: 2009-2010. Selected and edited by Kees van Raad. $8^{\text {th }}$ ed. The Hague: IBFD/ITC, 2009. v. 1.

. Options for greater international coordination and cooperation in the Tax Treaty Área. Bulletin for International Taxation, Amsterdam, IBFD, June 2002.

REPORT $t$ of the Fourth Session (20-24 October 2008) of the UN Committee of Experts on International Cooperation in Tax Matters, Economic and Social Council, Official Records, 2008. Supplement 25. Disponível em: <http://www.un.org/esa/ffd/tax/fourthsession/index.htm>. Acesso em: 07 jan. 2011.

REPORT of the Informal Consultative Group on the Taxation of Collective Investment Vehicles and Procedures for Tax Relief for Cross-Border Investors (ICG). Granting of Treaty Benefits with Respect to the Income of Collective Investment Vehicles. Draft Report for the OECD's Committee on Fiscal Affaires, 12 Jan. 2009. Disponível em: $<$ http://www.oecd.org/dataoecd/34/26/41974553>.

REUTER, Paul. Introducción al derecho de los tratados. Trad. Eduardo L. Suaréz. México: Fondo de Cultura Econômica, 1999.

REZEK, Francisco. Direito internacional público. 8 ed. São Paulo: Saraiva, 2000.

RIBEIRO, Hugo Fleischman Silvestre. Caso Hélio Castroneves: estruturação de investimento estrangeiro no Panamá e na Holanda e seus impactos fiscais. In: CASTRO, Leonardo Freitas de Moraes e. et al. (Orgs.). Tributação Internacional: análise de casos, Sao Paulo: MP Ed., 2010.

ROCHA, Maria Teresa Soler; RIBES, Aurora. Tax treaty interpretation in Spain. In: LANG, Michael (Coord.). Tax treaty interpretation. The Hague: Kluwer Law International, 2000. 
ROCHA, Roberto Paraíso. Brazilian report. In: IFA. Cahiers de Droit Fiscal Internacional: interpretation of double taxation conventions. Deventer: Kluwer Law International, 1993. v. 78.

ROCHA, Sérgio André. Interpretação dos tratados contra a bitributação da renda. Rio de Janeiro: Lúmen Júris, 2008.

—. Treaty override no ordenamento jurídico brasileiro. São Paulo: Quartier Latin, 2007.

RODAS, João Grandino. Tratados internacionais. São Paulo: Ed. Revista dos Tribunais, 1991.

ROLIM, João Dácio. A (des)necessidade de um conceito harmônico de "beneficiário efetivo" nos Acordos para evitar a dupla tributação: um caso brasileiro e o direito comparado. Revista Dialética de Direito Tributário, São Paulo, n. 179, p. 78-89, 2010.

. Normas antielisivas tributárias. São Paulo: Dialética, 2011.

ROSENBLOOM, David H. Tax treaty abuse: policies and issues. Law \& Policy International Business, v. 15, p. 763-764, 1983.

ROSSI, Marco Q. Tax treaties, beneficial ownership of income and domestic anti abuse measures: Italy's perspective. In: ABA Section of taxation foreign lawyers forum committee - Panel Presentation, Jan. 19, p. 3. 2007. Disponível em: $<$ http://www.lawrossi.com/images/stories/docs/THE_CONCEPT_BENEFICIAL_OWNER SHIP.pdf>. Acesso em: 28 dez. 2011.

ROTHMANN, Gerd W. Bitributação internacional. In: Temas fundamentais do direito tributário atual. Belém: CEJUP, 1983. p. 123-146.

A denúncia do acordo de bitributação Brasil-Alemanha e suas conseqüências.In: ROCHA, Valdir de Oliveira (Coord.). Grandes questões atuais do direito tributário. São Paulo: Dialética, 2005. v. 9.

Interpretação e aplicação dos acordos internacionais contra a bitributação. 1978.

Tese (Doutorado) - Faculdade de Direito da Universidade de São Paulo, 1978.

ROWLAND, Amanda. Beneficial ownership in a corporate context: what is it? When is it lost? Where does it go? British Tax Review, n. 3, 1997.

RUBINGER, Jeffrey. Tax planning with U.S. income tax treaties without LOB provisions. Tax Management International Journal, v. 36, n. 123, March 2007.

RUBINSTEIN, Flávio. Interpretação e aplicação dos acordos de bitributação: o papel da boa-fé objetiva. Revista de Direito Tributário Internacional, São Paulo, n. 3, jun. 2006. 
RUSSO, Antonio. Seminário Alumni Leiden de 2006: precedentes sobre interpretação dos tratados internacionais - caso indofood: conceito de beneficiário efetivo. Revista de Direito Tributário, São Paulo, n. 7, p. 217-221, 2007.

RUSSO, Raffaele. Fundamentals of international tax planning. Amsterdam: IBFD, 2007.

SACCHETTO, Cláudio. Direito internacional tributário. Revista de Direito Tributário Internacional, São Paulo, n. 5, 2007.

; TESSA, Barbara. Caso Valentino Rossi: riflessioni sull'accertamento com adesione quale instituto premiale in caso di contrasto sulla residenza fittizia delle persone fisiche. In: CASTRO, Leonardo Freitas de Moraes e. et al. (Orgs.). Tributação Internacional: análise de casos, Sao Paulo: MP Ed., 2010.

SANTIAGO, Igor Mauler. Direito tributário internacional: métodos de solução de conflitos. São Paulo: Quartier Latin, 2006.

SCHOUERI, Luís Eduardo. Contribuição à história dos acordos de bitributação: a experiência brasileira. Direito Tributário Atual, São Paulo, n. 22, p. 267-287, 2008.

Direito tributário internacional. Acordos de bitributação. Imposto de renda: lucros auferidos por controladas e coligadas no exterior. disponibilidade. Efeitos do artigo 74 da Medida Provisória no 2.158-35 - Parecer. In: Direito Tributário Atual, n. 16, p. 198, São Paulo: IBDT/Dialética, 2011.

Direito tributário internacional: qualificação e substituição - tributação, no Brasil, de rendimentos provenientes de sociedade de pessoas residente na Alemanha. Revista Dialética de Direito Tributário, São Paulo, n. 54, p. 125-139, 2000.

Planejamento fiscal através de acordos de bitributação: treaty shopping. São Paulo: Ed. Revista dos Tribunais, 1995.

—. Preços de transferência no direito tributário brasileiro. São Paulo: Dialética, 1999.

- Preços de transferência no direito tributário brasileiro. 2 ed. São Paulo: Dialética, 2006.

- Princípios no direito tributário internacional: territorialidade, fonte e universalidade. In: FERRAZ, Roberto Catelano Botelho (Org.). Princípios e limites da tributação. 1. ed. São Paulo, Quartier Latin, 2005. v. 1.

Tratados e convenções internacionais sobre tributação. Direito Tributário Atual, São Paulo, n. 17, 2003. 
SHARKEY, Nolan Cormac. China's tax treaties and beneficial ownership: innovative control of treaty shopping or inferior law making damaging to international law? Bulletin of International Taxation, Amsterdam, v. 65, n. 12, 2011.

SHEPPARD, Lee. Indofood and bank of Scotland: who is the beneficial owner. Tax Notes International, v. 45, n. 5, p. 406, 2007.

SILVA, Virgílio Afonso da. Princípios e regras: mitos e equívocos acerca de uma distinção. Revista Latino-Americana de Estudos Constitucionais, n. 1, 2003, p. 607-630. Disponível em: <http://direitosfundamentais.net/2008/06/03/ainda-as-regras-e-osprincipios-o-artigo-de-virgilio-afonso-da-silva/>. Acesso em: 12 out. 2011.

SILVEIRA, Rodrigo Maitto da. Aplicação de tratados internacionais contra a bitributação: qualificação de partnership joint ventures. São Paulo: Quartier Latin, 2006. (Série Doutrina Tributária v. 1).

. O escopo pessoal na aplicação dos acordos internacionais contra a bitributação. 2009. Dissertação (Mestrado). Faculdade de Direito da Universidade de São Paulo, 2009.

SPEED, Robin. Beneficial ownership. Australian Tax Review, nr. 3, p. 46-46, 1997.

TAVOLARO, Agostinho Toffoli. Beneficiário efetivo. Revista Tributária e de Finanças Públicas, São Paulo, n. 52, 2003.

- Tratado Brasil/Estados Unidos para evitar a dupla tributação. Revista de Direito Tributário Internacional, São Paulo, v. 15, 2010.

TAX COURT OF CANADA. Disponível em: <http://decision.tcccci.gc.ca/en/dn/2008/04.html>. Acesso em: 08 mar. 2011.

TEIXEIRA, Alessandra Machado Brandão. O conceito de beneficiário efetivo nos convênios para evitar dupla imposição como prevenção da elisão fiscal internacional. In: COLÓQUIO INTERNACIONAL DE DIREITO TRIBUTÁRIO, 5. Buenos Aires: La Ley, 2003.

TOIT, Charl P. du. Beneficial ownership of royalties in bilateral tax treaties. Amsterdam: IBFD, 1999.

TÔRRES, Heleno Taveira. A convenção Brasil-Alemanha e sua aplicação em face do direito brasileiro. Revista de Direito Tributário, São Paulo, n. 83, 2002.

Direito tributário e direito privado: autonomia privada, simulação e elusão tributária. São Paulo: Ed. Revista dos Tribunais, 2003. 
TÔRRES, Heleno Taveira. Dupla (Múltipla) tributação internacional. Rendas de empresas: 'dupla tributação jurídica internacional' e 'dupla tributação econômica internacional'. Revista de Direito Tributário, São Paulo, n. 65, p. 68, 1995.

A interpretação dos tratados internacionais em matéria tributária sobre a renda e o capital. In: FUNDACIÓN DE CULTURA UNIVERSITARIA. Estudios en memória de Ramón Valdés Costa. 1. ed. Fundación de Cultura Universitária, 1999. v. 1.

Pluritributação internacional sobre as rendas de empresas. 2. ed. São Paulo: Ed. Revista dos Tribunais, 2001.

TORRES, Ricardo Lobo. Normas de interpretação e integração do direito tributário. 4. ed. Rio de Janeiro: Renovar, 2006.

UCHÔA FILHO, Sérgio Papini de Mendonça. Caso Agassi: análise da tributação internacional de rendimentos dos contratos de patrocínio de esportistas: um novo conceito de fonte? In: CASTRO, Leonardo Freitas de Moraes e. et al. (Orgs.). Tributação Internacional: análise de casos, Sao Paulo: MP Ed., 2010.

; CASTRO, Leonardo Freitas de Moraes e. Thin capitalization rules no direito comparado e as regras de subcapitalização brasileiras. Revista de Direito Tributário Internacional, São Paulo, v. 15, p. 169-211, 2010.

US DEPARTMENT OF TREASURY. United States Techincal Explanation Accompanying the United States Model Income Tax Convention, Article 12, Paragraph 174, of. September 20, 1996. Disponível em: $<$ http://www.irs.gov/businesses/small/international/article/0,,id=164686,00.html>. Acesso em: 21 out. 2011.

US Model Income Tax Convention, Sept. 20, 1996. Disponível em: $<$ http://www.irs.gov/businesses/international/article/0,,id=169597,00.html>. Acesso em: 20 dez. 2011.

VALDES, Miguel A.; PAOLI, Amanda de. O conceito de beneficiário efetivo nos convênios para evitar dupla imposição, como prevenção da elisão fiscal internacional. In: In: COLÓQUIO INTERNACIONAL DE DIREITO TRIBUTÁRIO, 5. Buenos Aires: La Ley, 2003.

VASCONCELLOS, Roberto França. Aspectos econômicos dos tratados internacionais em matéria tributária. Revista de Direito Tributário Internacional, São Paulo, n. 1, p. 147 e ss., 2005 .

VEJA BORREGO Félix Alberto. Limitation on benefits clauses in double taxation conventions. The Hague: Kluwer Law International, 2006. (EUCOTEX Series on European Taxation). 
VENKATESWARLU, Sistla; DROLIA, Suruchi. India: tax implications of cross-boarder M\&A. Tax Planning International Review, London, v. 38, n. 11, Nov. 2011.

VOGEL, Klaus. The domestic law perspective. In: MAISTRO, Guglielmo (Org.). Tax treaties and domestic law. Amsterdam: IBFD, 2006.

Influence of the OECD commentaries on treaty interpretation. Bulletin - tax treaty monitor, Amsterdam, p. 615, Dec. 2000.

Klaus Vogel on double taxation conventions: a commentary to the OECD, UN and US model conventions for the avoidance of double taxation of income and capital with particular reference to German treaty practice. 3rd ed. Boston: Kluwer Law International, 1997.

Problemas na interpretação de acordos de bitributação. In: SCHOUERI, Luis Eduardo (Coord.). Direito Tributário (Homenagem a Alcides Jorge Costa). São Paulo: Quartier Latin, 2003. v. 2, p. 964-966.

; PROKISCH, Rainer. General Report. In: IFA. Cahiers de Droit Fiscal Internacional: interpretation of double taxation conventions. Florence, Deventer: Kluwer Law International, 1993. v. 78.

(Chair). The OECD Model Convention - 1998 and Beyond; The Concept of Beneficial Ownership in Tax Treaties - Proceedings of a Seminar held in London, in 1998 during the $52^{\text {nd }}$ Congress of the International Fiscal Association. The Hague: Kluwer Law International, 2000. v. 23a.

WALKER, David M. The Oxford companion to law. Oxford: Claredon Press, 1980.

WALSER, J. In: VOGEL, Klaus (Chair). The OECD Model Convention - 1998 and Beyond; The Concept of Beneficial Ownership in Tax Treaties - Proceedings of a Seminar held in London, in 1998 during the $52^{\text {nd }}$ Congress of the International Fiscal Association. The Hague: Kluwer Law International, 2000. v. 23a.

WEEGHEL, Stef van. The improper use of tax treaties: with particular reference to the Netherlands and the United States. London: Kluwer Law International, 1998. (Series of International Taxation n. 19).

WHEELER, Joanna C. Conflicts in the attribution of income to a person. In: IFA: General Report. Cahiers de Droit Fiscal International, Amersfoort, v. 92, 2007.

WIMAN. In: VOGEL, Klaus (Chair). The OECD Model Convention - 1998 and Beyond; The Concept of Beneficial Ownership in Tax Treaties - Proceedings of a Seminar held in London, in 1998 during the $52^{\text {nd }}$ Congress of the International Fiscal Association. The Hague: Kluwer Law International, 2000. v. 23a. 
XAVIER, Alberto. Direito internacional tributário do Brasil. 6. ed. Rio de Janeiro: Forense, 2004.

YAMASHITA, Douglas. Elisão e evasão de tributos - planejamento tributário: limites à luz do abuso de direito e da fraude à lei. São Paulo: Lex, 2005.

ZIMMER, Frederik. General Report: form and substance in tax law. In: IFA: Cahiers de Droit Fiscal International. Kluwer, 2002. v. 87.

ZORNOZA, Juan José; BÁEZ, Andrés. The 2003 revisions to the commentary to the OECD on tax treaties and GAARs: a mistaken starting point. In: LANG, Michael et al. (Ed.). Tax treaties: building bridges between law and economics. Amsterdam, IBFD, 2010. 